\title{
Co-variance nexus between ultraviolet index and tropospheric ozone during COVID-19 lockdown over megacities of India
}

Biswajit Bera ( $\sim$ biswajitbera007@gmail.com )

Sidho-Kanho-Birsha University https://orcid.org/0000-0002-0957-8023

Sumana Bhattacharjee

Jogesh Chandra Chaudhuri College

Pravat Kumar Shit

Raja Narendra Lal Khan Women's College

Nairita Sengupta

Diamond Harbour Women's University

Soumik Saha

University of Calcutta

\section{Research Article}

Keywords: COVID-19, UV index, concentration of 03, lockdown phase

Posted Date: March 13th, 2021

DOI: https://doi.org/10.21203/rs.3.rs-297076/v1

License: (c) (1) This work is licensed under a Creative Commons Attribution 4.0 International License.

Read Full License 
Co-variance nexus between ultraviolet index and tropospheric ozone during COVID-19 lockdown over megacities of India

Biswajit Bera ${ }^{1 *}$, Sumana Bhattacharjee ${ }^{2}$, Pravat Kumar Shit ${ }^{3}$, Nairita Sengupta ${ }^{4}$, Soumik Saha ${ }^{5}$

${ }^{1}$ Department of Geography, Sidho-Kanho-Birsha University, Ranchi Road, P.O. Purulia Sainik School, 723104, India. E-mail: biswajitbera007@gmail.com

${ }^{2}$ Department of Geography, Jogesh Chandra Chaudhuri College (University of Calcutta), 30, Prince Anwar Shah Road, Kolkata 700 033, India. E-mail: sumana.aarohi@ gmail.com

${ }^{3}$ Department of Geography and Environment Management, Raja Narendralal Khan Women's College, Gope Palace, P.O. Vidyasagar University, Paschim Medinipur, 721102, India. E-mail: shitpravat2013@gmail.com

${ }^{4}$ Department of Geography, Diamond Harbour Women's University, Sarisha,743368, India. E-mail: nairitasengupta2@gmail.com

${ }^{5}$ M.A., Independent Scholar. E-mail: soumiksaha577@gmail.com

\section{* Corresponding author.}

\section{Biswajit Bera}

Department of Geography, Sidho-Kanho-Birsha University, Ranchi Road, P.O. Purulia Sainik School, 723104, India.

E-mail: biswajitbera007@gmail.com 


\title{
Co-variance nexus between ultraviolet index and tropospheric ozone during COVID-19 lockdown over megacities of India
}

\begin{abstract}
Worldwide spread out of COVID-19 in a short-time has brought a significant decline of road traffic, tourist flow and industrial ventures. During this emergency period, the restricted human dealings with nature have appeared as blessing for health of the total environment. The variation of atmospheric $\mathrm{O}_{3}$ may modulate the range of $\mathrm{UV}$ index (UVI) at any region of the earth. The objective of the study is to examine the alteration of UV index over the megacities of India with respect to tropospheric $\mathrm{O}_{3}$ level modification during COVID-19 lockdown. The spatiotemporal data of UVI, over the major megacities of India (New Delhi, Mumbai, Kolkata, and Chennai) have been extracted from Tropospheric Emission Monitoring Internet Service. The monthly average surface ozone concentration throughout the time frame of 2019 and 2020 has been obtained from NASA Earth Observatory (NEO) hub. The meteorological or environmental data (temperature in ${ }^{\circ} \mathrm{C}$, gust in $\mathrm{km} / \mathrm{h}$, wind speed $\mathrm{km} / \mathrm{h}$, relative humidity in \%, air pressure in mb and cloud cover in okta) of four selective megacities of India (Kolkata, Chennai, Delhi, Mumbai) during and pre lockdown period have been acquired from world weather online. The descriptive statistical applications i.e. standard deviation, standard errors and K-means clustering have been done through standard statistical software. The result shows that the four major megacities in India namely New Delhi, Mumbai, Kolkata and Chennai have experienced the vibrant diminution in terms of the concentration of UV index with slightly increasing the tropospheric $\mathrm{O}_{3}$ level during the lockdown phase. In the meantime, the prominent reduction of $\mathrm{NO}_{\mathrm{x}}$ during the lockdown period decreases the titration impact to $\mathrm{O}_{3}$ and this mechanism helps to revitalize the ozone concentration level. The uniqueness of the current study is highlighted the ground reality regarding reduction of UV index and amplification of tropospheric $\mathrm{O}_{3}$ concentration during lockdown phase. This study definitely assists to make new environmental policy, act and law for recover the health of the total environment.
\end{abstract}

Keywords: COVID-19; UV index; concentration of $\mathrm{O}_{3}$; lockdown phase. 


\section{Introduction}

The brutal hit of novel coronavirus (COVID-19) modifies the systematic tempo of global social, political, economic, cultural arena as well as the global citizens are bounded to encounter the dreadful tremor of COVID19. On $30^{\text {th }}$ January 2020, the World Health Organization (WHO) announced COVID-19 disease as sixth Public Health Emergency of International Concern considering its devastating consequences all over the world (Wee et al. 2020; WHO 2020a). COVID-19, emerged from novel coronavirus SARS-CoV-2, has been designated as pandemic on $11^{\text {th }}$ March 2020 by WHO (WHO 2020b). After detecting the first confirmed case in December 2019 at Wuhan city in China (Huang $C$ et al. 2020; Zhou et al. 2020; Zhu et al. 2020), the fatal contagion is gushed speedily through physical contacts. In this aspect, maintenance of social isolation is regarded as the social medicine to prevent the deadly impacts of this noxious infectious disease and worldwide almost all governments have imposed this social distancing norms to combat the disastrous outbreak of COVID-19 (Huang X et al. 2020;

Zhang et al. 2020). India holds the leading position in the list of world's worst affected countries with 46,188 deaths and 23,28,405 confirmed cases as of $11^{\text {th }}$ August, 2020 (covid19india.org). In India, social distancing rules and lockdown has been strictly imposed from $25^{\text {th }}$ March 2020 and then it has been extended up to $31^{\text {st }}$ May 2020 into four phases to fight with the menace of coronavirus during this acute crisis period.

During the lockdown period, the halting of transport movement, industrial activities and power generation ensure the cleanliness of atmosphere, refurbishment of ozone layer and purification of the total environment (Chakraborty and Maity 2020). Although, the health and economic sectors must fight against the noxious effects of COVID-19 while the pausing of anthropogenic activities restrains the magnitude of pollution (Dutheil et al. 2020). It must be remarkable that the global atmospheric quality as well as health of total environment has been restored at a certain limit because of restricted burnings of fuels, partly shut down of industrial production and transportation activities (Muhammad et al. 2020). The usage of energy resources and consumption of materials is effectively dwindled due to the imposition of long-term lockdown (Jribi et al. 2020). It must be stated that the alteration of $\mathrm{NO}_{2}$ level is remarkably prominent over Asian countries during COVID-19 lockdown while in India $\mathrm{NO}_{2}$ is sharply reduced by $70 \%$ amidst this global emergency (Gautam 2020). The previous study has pointed out that the concentration of $\mathrm{SO}_{2}, \mathrm{NO}_{2}, \mathrm{CO}_{2}, \mathrm{O}_{3}, \mathrm{PM}_{10}$ and $\mathrm{PM}_{2.5}$ has been investigated over the 22 cities of India during the month of March and April, 2020 in comparison with the identical time frame during 2017 and this assessment depicts the cheering picture in terms of air quality up gradation during lockdown period (Sharma et 
al. 2020). In this context, it must be mentioned that ozone $\left(\mathrm{O}_{3}\right)$ is a significant parameter for examining the air quality modifications. During COVID-19 lockdown phase, $\mathrm{O}_{3}$ accumulation is substantially amplified over Yangtze river delta area in China (Li et al. 2020) and Sao Paulo in Brazil (Nakada and Urban 2020) which is considered as a positive sign for ecological wellbeing. In Kolkata Metropolitan city (India), $\mathrm{SO}_{2}, \mathrm{NO}_{2}, \mathrm{CO}, \mathrm{PM}_{2.5}$ and $\mathrm{PM}_{10}$ have been amazingly lowered during lockdown period while concentration of $\mathrm{O}_{3}$ is magnified to some extent compared with the pre-lockdown period (Bera et al. 2020). In the atmosphere, $\mathrm{O}_{3}$ has a crucial contribution in the aspect of physicochemical mechanisms over troposphere, nevertheless it plays a vital role to heighten the oxidizing capability of the lower atmosphere. The surface $\mathrm{O}_{3}$ may exert detrimental impacts for natural vegetation, agricultural yields along with animal community and mankind (Bates 1994; Finlayson-Pitts and Pitts 1997; Hogsett et al. 1997; Wang et al. 2003; Garcia et al. 2005; Jerrett et al. 2009; Nishanth et al. 2014) if its presence exceeds the permissible limit $\left(200 \mu \mathrm{g} / \mathrm{m}^{3}\right.$ or $0.2 \mathrm{mg} / \mathrm{m}^{3}$ or $\left.0.1 \mathrm{ppm}\right)$ in the troposphere (Bera et al. 2020).The tropospheric $\mathrm{O}_{3}$ is categorised as secondary air pollutant and its origin is related with the composite photochemical procedures in the existence of volatile organic compounds (VOC), nitrogen oxides (NOx) and carbon monoxide (CO) which regulate the balance of surface $\mathrm{O}_{3}($ Fishman and Crutzen 1977, 1978; Garcia et al. 2005). Several previous research reports highlighted that maximum accumulation of $\mathrm{O}_{3}$ had been recorded during the ending phase of autumn and entire winter season and this phenomenon is continued over the month of May in India (Varshney and Aggarwal 1992; Lal et al. 2000; Naja and Lal 2002; Nair et al. 2002 ; Jain et al. 2005; Beig et al. 2007; Ghude et al. 2008).

It must be stated that $\mathrm{O}_{3}$ is such an atmospheric constituent only which has the competency to captivate solar ultraviolet ray (UVR) within the range of $2000^{\circ} \mathrm{A}-3000^{\circ} \mathrm{A}$ and this phenomenon expressively guard the biota of the earth from life-threatening exposure to the noxious UV ray (Brasseur and Solomon 1986). Ultraviolet radiation is divided into three categories i.e. UV-A (315-400 nm), UV-B (280-315 nm) and UV-C (200-280 nm). Atmospheric ozone has the potentiality to engross all types of UV-C rays and the captivation capacity of $\mathrm{O}_{3}$ has been augmented in terms of the reduction in wavelength of UV-B radiation (Fioletov et al. 2010). UV radiation is the principal and highly avoidable threat for skin cancer of innumerable people globally. This harmful radiation can weaken the human immunity system and it is severely injurious for eyes and skin (Meves et al. 2003).Ultraviolet or UV index (UVI) had been introduced to estimate the diurnal magnitude of UVR at a certain point of time and space in a consistent manner (Gies et al. 2018). The UV index had been propounded during 1992 in Canada and it had accepted by the Environmental Protection Agency (EPA) and United States National Weather Service (NWS) along with the World Health Organization (WHO) and World Meteorological Organization 
(WMO) during 1994. This concept was first documented during 1995 and later it had been revised during 2002 to modify its effectiveness as a means of rising peoples' consciousness about the probable troubles regarding UVR (WHO et al. 2002). Fundamentally, the Global Solar Ultraviolet Index (UVI) defines the intensity of ultraviolet ray upon the surface of the earth and the high range of UVI indicates the speedy and acute damaging impact on human health (WHO et al. 2002). The UVI assists to analyse the ultraviolet related morbidities and contributes to develop a robust perception among human being about their vulnerability towards the risk of UVR (Gies et al. 2018).The magnitude of UVI is generally persisted at higher range over the tropical regions compared with the poles. The highly populous megacities of India are not the exception in this aspect as they also register the greater range of Solar Ultraviolet Index. The fact is noteworthy that the variation in atmospheric $\mathrm{O}_{3}$ level may modulate the range of UVI at any region of the earth surface. In this context, it must be stated that the four major megacities in India namely Delhi, Mumbai, Kolkata and Chennai have experienced the vibrant modifications in terms of the toxic air pollutants concentration including $\mathrm{O}_{3}$ during the lockdown phase (CPCB 2020; Sharma et al. 2020; Lau et al. 2020; Bera et al. 2020). The main objective of the study is to examine the change of UV index in New

Delhi, Mumbai, Kolkata and Chennai and correlation between tropospheric $\mathrm{O}_{3}$ and UV index during COVID-19 lockdown compared with the preceding year. The study has enormous significance or importance because the short-term lockdown brings remarkable reduction of UV index as well as slight progress of tropospheric $\mathrm{O}_{3}$. Several scientific studies proved that UV radiation has multidimensional direct and indirect health effects. Meanwhile, the COVID-19 global pandemic offers multidimensional research wings for researchers, scholars and scientists. Subsequently, policymakers and administrators can make sustainable environmental management plan from contemporary research findings.

\section{Methods and material}

\subsection{Data sources and data acquisition}

In the present study, the variation of UV index has been analysed in the presence of the altered surface ozone accumulation during lockdown phase. The four important megacities of India such as New Delhi, Mumbai, Kolkata and Chennai have been selected for this purpose and the time span from $25^{\text {th }}$ March to $31^{\text {st }}$ May of 2019 and 2020 has been determined to examine the changing pattern of UVI and surface $\mathrm{O}_{3}$ concentration during and pre lockdown period. The monthly average surface ozone concentration throughout the time frame of the year 2020 and 2019 has been obtained from NASA Earth Observatory (NEO) hub (https://neo.sci.gsfc.nasa.gov/) for 
comparative analysis of tropospheric ozone accumulation over the selective four megacities during and pre lockdown session(NEO 2020). The spatiotemporal data of UVI, tropospheric $\mathrm{O}_{3}$ concentration along with UVI intensity data over the major megacities of India (New Delhi, Mumbai, Kolkata, and Chennai) during the sampling period have been extracted from Tropospheric Emission Monitoring Internet Service (http://www.temis.nl/index.php)(TEMIS 2020). The diurnal climatological data (temperature in ${ }^{\circ} \mathrm{C}$, gust in $\mathrm{km} / \mathrm{h}$, wind speed $\mathrm{km} / \mathrm{h}$, relative humidity in $\%$, air pressure in $\mathrm{mb}$ and cloud cover in okta) of four selective megacities of India (Kolkata, Chennai, Delhi, Mumbai) during and pre lockdown period have been obtained from world weather online(https://www.worldweatheronline.com/) (Supplementary Table S3, S4, S5, S6).
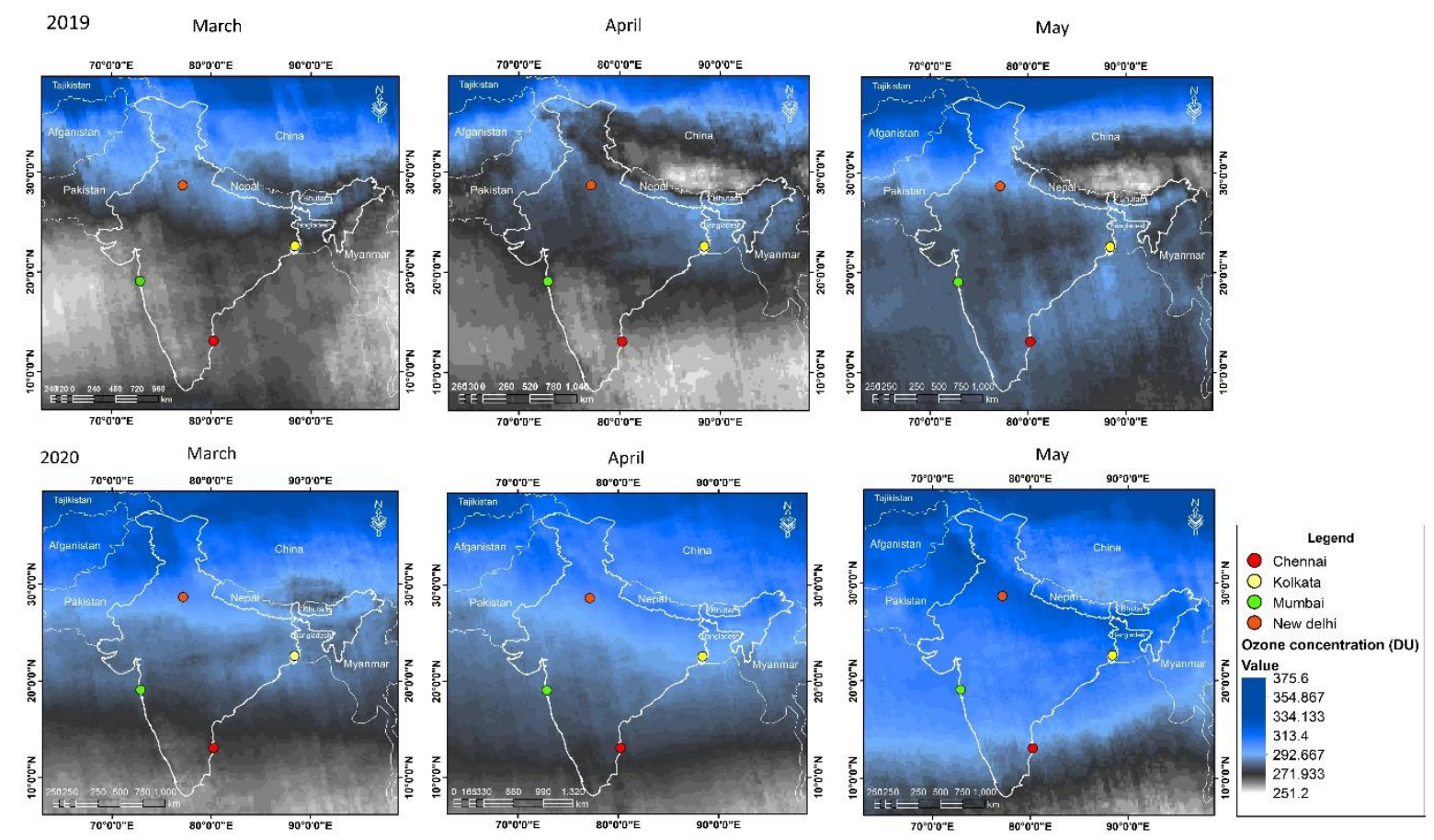

Fig. 1 The fluctuation of tropospheric ozone concentration over the megacities of India during 2019-2020

$\left(25^{\text {th }}\right.$ March $-31^{\text {st }}$ May $)$

\subsection{Data analysis}

\subsubsection{Statistical analysis along with RS and GIS techniques}

The diurnal and monthly average as well as the percentage of tropospheric $\mathrm{O}_{3}$ and UVI has been determined individually for each selective megacity during and pre lockdown period to identify changing trend of the two variables during the sampling period in 2020 compared with the previous year. The relevant statistical applications are used to deduce the proper inter-relation and consistency level among the selected variables (Bera et al. 2019). 
In this study, Pearson correlation coefficient (R) has been applied on the Grapher 13 software platform to determine the strength of the correlation among the two selective variables i.e. surface $\mathrm{O}_{3}$ and UVI over the four megacities during the sampling period of the year 2019 and 2020. Moreover, the descriptive statistical applications i.e. standard deviation, standard errors have been estimated to identify the temporal variation of surface $\mathrm{O}_{3}$ and UVI over New Delhi, Mumbai, Kolkata and Chennai (Table 1). In the current study, ' $t$ ' test has been applied to comprehend level of significance of surface $\mathrm{O}_{3}$ and UVI during pre-lockdown (2019) and lockdown (2020) phase (Supplementary Table S7). The ' $t$ ' test has been performed here to measure if there is a substantial variation between the two variables. The important steps ("t-test") are given below -

$$
\begin{aligned}
& t=\frac{\bar{x}_{1}-\bar{x}_{2}}{\sqrt{s^{2}\left(\frac{1}{n_{1}}+\frac{1}{n_{2}}\right)}}(1) \\
& s^{2}=\frac{\sum_{i=1}^{n_{1}}\left(x_{i}-\bar{x}_{1}\right)^{2}+\sum_{j=1}^{n_{2}}\left(x_{j}-\bar{x}_{2}\right)^{2}}{n_{1}+n_{2}-2}(2)
\end{aligned}
$$

Where $\overline{\boldsymbol{x}} 1$ and $2=$ sample average of different groups. $\mathrm{S}^{2}=$ sample variance where as $\mathrm{n}_{1}$ and $\mathrm{n}_{2}=$ sample sizes of variables.

Table 1 Paired sample statistics of tropospheric $\mathrm{O}_{3}$ and UVI (2019-2020)

\begin{tabular}{cccccc}
\hline Year & $\begin{array}{c}\text { Selective } \\
\text { variables }\end{array}$ & Mean & N & $\begin{array}{c}\text { Standard } \\
\text { Deviation }\end{array}$ & $\begin{array}{c}\text { Standard Error } \\
\text { Mean (SE) }\end{array}$ \\
\hline $\mathbf{2 0 1 9}$ & $\mathrm{O}_{3}$ & 274.14 & 272 & 10.449 & 0.634 \\
& $\mathrm{UVI}$ & 12.5789 & 272 & 1.07301 & 0.06506 \\
$\mathbf{2 0 2 0}$ & $\mathrm{O}_{3}$ & 284.20 & 272 & 11.904 & 0.722 \\
& $\mathrm{UVI}$ & 11.9913 & 272 & 1.14784 & 0.06960 \\
\hline
\end{tabular}


Moreover, K-means clustering technique has been used to find out the similarities among the four selective megacities in terms of ground-level $\mathrm{O}_{3}$ and UVI concentration during (2020) and pre lockdown (2019) period. Kmeans clustering is a simplest unsupervised machine learning algorithm which is applied in this study through statistical software. This unsupervised algorithm is initiated with a first group of randomly selected centroids. It also attempts to develop the intra cluster data points as similar as possible. The process of k-means clustering is called the Expectation Maximization. The two steps of K-means clustering are as follows -

Assignment step (It means to divide the observations according to Voronoi diagram) -

$$
S_{i}^{(t)}=\left\{x_{p}:\left\|x_{p}-m_{i}^{(t)}\right\|^{2} \leq\left\|x_{p}-m_{j}^{(t)}\right\|^{2} \forall j, 1 \leq j \leq k\right\}(3)
$$

Update step (Centroids for the observations)

$$
m_{i}^{t+1}=\frac{1}{\left|s_{i}^{(t)}\right|} \sum_{x_{j \in} s_{i}^{(t)}} x_{j}(4)
$$

Alongside, the graphical representations have been accomplished based on the average value of $\mathrm{O}_{3}$ and UVI during the sampling time frame in 2019 and 2020 using Grapher 13 software. The correlation matrix (according to Pearson's method) has also been applied to determine the interrelationship of ultra violet index and $\mathrm{O}_{3}$ with various climatological criteria. Furthermore, relevant digital thematic maps have been produced on the basis of the monthly average tropospheric ozone concentration data with the help of Arc GIS 10.3 software.

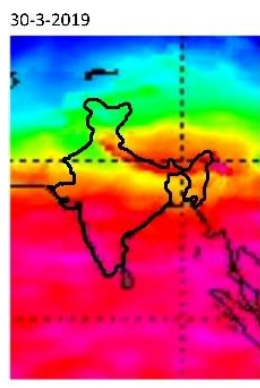

30-3-2020

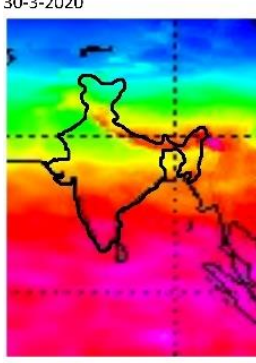

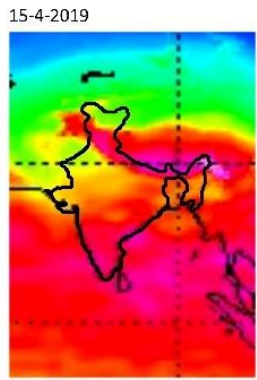

$15-4-2020$

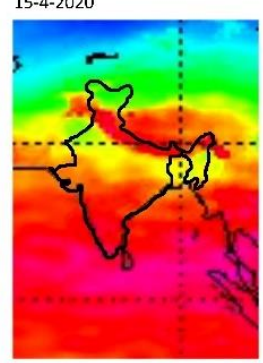

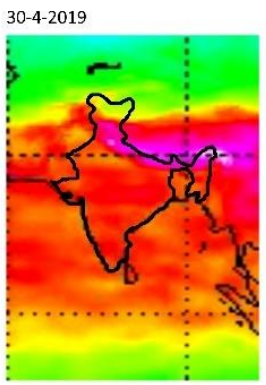

30-4-2020

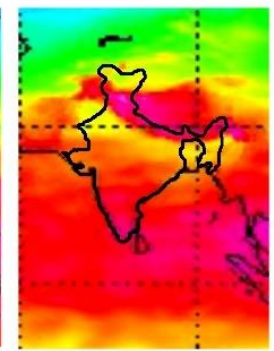

UVI value

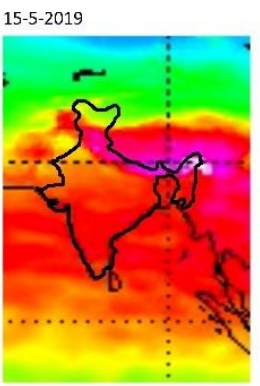

15-5-2020
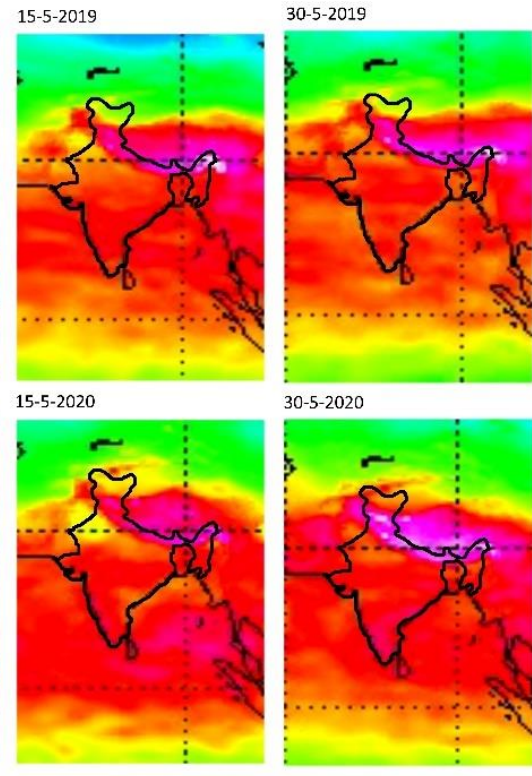

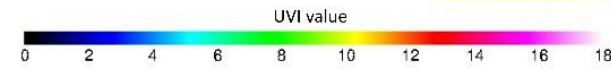

Fig. 2 The alteration of ultraviolet index (UVI) throughout India during and pre lockdown phase (2019- 


\section{Results}

\subsection{Modification of tropospheric $\mathrm{O}_{3}$ concentration during and pre-lockdown phase}

The present study illustrates that the concentration of $\mathrm{O}_{3}$ is slightly amplified over the selected four megacities in India during lockdown session $\left(25^{\text {th }}\right.$ march to $31^{\text {st }}$ May), 2020 compared with the pre lockdown year, 2019 (Fig.1). Concurrently, reduction of the UV index has been registered over these particular regions amidst the same time period in the year 2020. During the lockdown phase, the highest average accumulation of tropospheric $\mathrm{O}_{3}(302.54$ $\mathrm{du}$ ) has been recorded over New Delhi in the month of April, 2020 whereas in this megacity, the $\mathrm{O}_{3}$ concentration level was 278.48 du during the identical month of pre lockdown scenario, 2019. It must be noticeable that the modification of surface $\mathrm{O}_{3}$ level over New Delhi, Mumbai, Kolkata and Chennai has been varied within the range of 47.93\% - 52.07\% during the quarantine session in 2020 (Table 2; Fig. 3; Supplementary Table S1). In Mumbai, the $\mathrm{O}_{3}$ concentration was recorded around $48.21 \%$ within $25^{\text {th }}$ March to $31^{\text {st }}$ March, 2019 during prelockdown scenario whereas it has been risen up to $51.79 \%$ in the same time frame of 2020 during lockdown period. The average monthly presence of surface $\mathrm{O}_{3}$ is improved by $2.28 \%$ over Kolkata in April during lockdown phase in comparison with the same month of 2019. It must be noteworthy that the increasing rate of surface $\mathrm{O}_{3}$ is substantially declined in May, 2020 in comparison with April, 2020 over New Delhi (1.58\%), Mumbai (0.9\%) and Kolkata (1.94\%) while Chennai has exceptionally witnessed the decreasing trend of $\mathrm{O}_{3}(0.18 \%)$ in the month of May, 2020 (275.8 du) compared with May, 2019 (274.83 du) during pre-lockdown stage (Table 2; Fig. 3; Supplementary Table S1).

Table 2 Monthly average concentration, percentage and changing share of surface $\mathrm{O}_{3}$ during and pre lockdown phase in the major megacities of India

\begin{tabular}{cccccc}
\hline $\begin{array}{c}\text { Name of the } \\
\text { megacities }\end{array}$ & Year & Month & $\begin{array}{c}\text { Surface O3 } \\
(\mathbf{d u})\end{array}$ & $\begin{array}{c}\text { Surface O3 } \\
(\boldsymbol{\%})\end{array}$ & $\begin{array}{c}\text { Share of } \\
\text { change (\%) }\end{array}$ \\
\hline New Delhi & 2019 & March & 284.01 & 49.23 & - \\
& 2020 & & 292.93 & 50.77 & +1.54 \\
& 2019 & April & 278.48 & 47.93 & - \\
& 2020 & & 302.54 & 52.07 & +4.14 \\
& 2019 & May & 282.55 & 49.21 & - \\
Mumbai & 2020 & & 291.61 & 50.79 & +1.58 \\
& 2019 & March & 257.39 & 48.21 & - \\
& 2020 & & 276.54 & 51.79 & +3.58 \\
& 2019 & April & 267.24 & 48.95 & - \\
\hline
\end{tabular}




\begin{tabular}{cccccc}
\hline 2020 & & 278.68 & 51.05 & +2.1 \\
2019 & May & 277.62 & 49.55 & - \\
Kolkata & & 282.71 & 50.45 & +0.9 \\
& 2020 & & 264.86 & 49.22 & - \\
& 2019 & March & 273.21 & 50.78 & +1.56 \\
& 2019 & & 277.29 & 48.86 & - \\
& 2020 & April & 290.24 & 51.14 & +2.28 \\
& & & 273.27 & 49.03 & - \\
& 2019 & May & 284.03 & 50.97 & +1.94 \\
& 2020 & & 48.9 & - \\
& 2019 & March & 259.83 & 51.1 & +2.2 \\
& 2020 & & 271.47 & 49.37 & - \\
& 2019 & April & 267.58 & 50.63 & +1.26 \\
& 2019 & & 274.38 & 50.09 & - \\
& 2020 & May & 275.8 & 49.91 & -0.18 \\
\hline
\end{tabular}

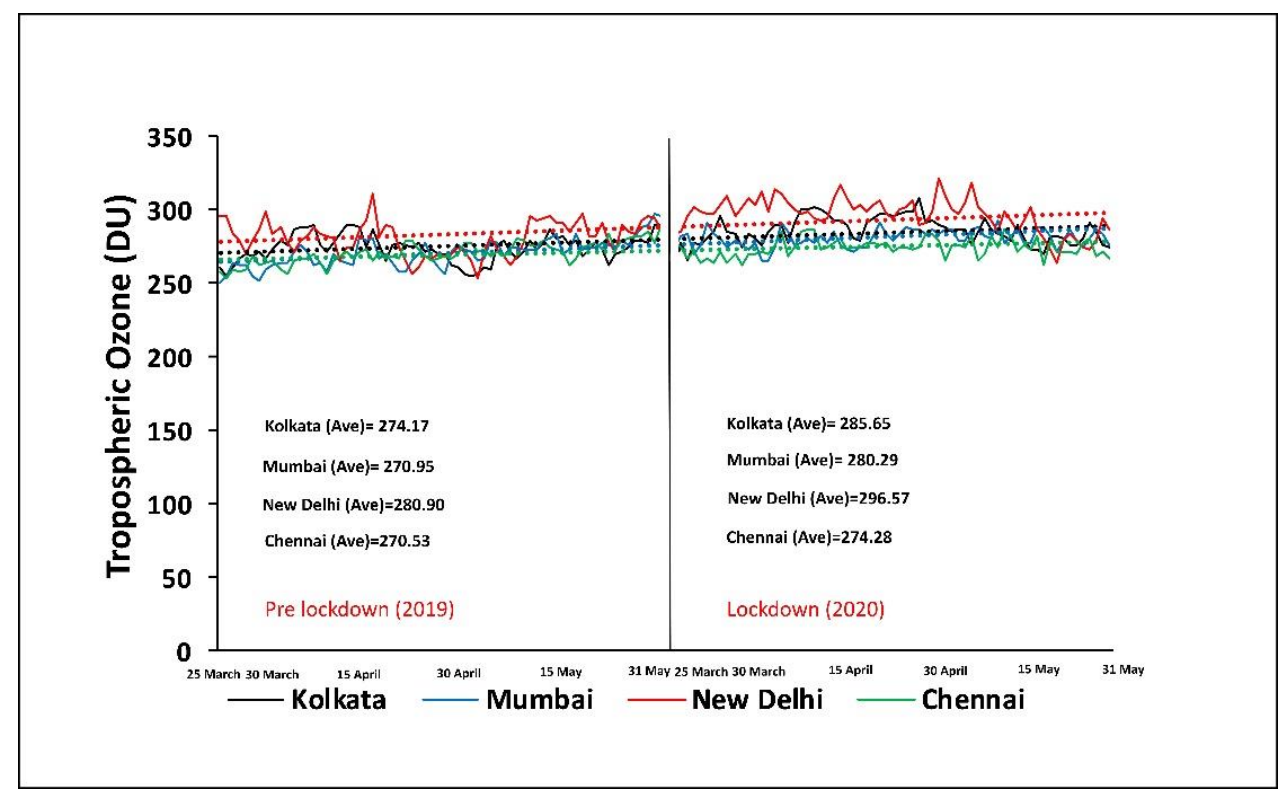

Fig. 3 The changing pattern of tropospheric $\mathrm{O}_{3}$ through the sampling period $\left(25^{\text {th }}\right.$ March $-31^{\text {st }}$ May) during and pre lockdown period (2019-2020)

\subsection{Fluctuations of UV index over four major megacities}

On the other side, the present study portrays that the UV index has been diminished at a significant rate in terms of the magnification of $\mathrm{O}_{3}$ in lower atmosphere over the four important megacities of India during lockdown period compared with pre-lockdown. The dropping of UVI during the quarantine session in 2020 has been 
distinctly depicted in different pockets of India (Fig.2). During the lockdown scenario, the UV index is prominently altered within the range of 9.2 to 13.84 which vividly indicates about $1.3 \%$ to $5.72 \%$ lessening of UVI over New Delhi, Mumbai, Kolkata and Chennai in comparison with the previous year, 2019 (Table 3; Fig. 4; Supplementary Table S2). In New Delhi during the month of April 2020, the UV index is decreased around 9.99 from 11.2 in April, 2019 whereas UVI has been diminished by 4.84\% in Mumbai during March $\left(25^{\text {th }}\right.$ March to $31^{\text {st }}$ March) of 2020 compared with the identical time period during pre-lockdown phase in the year 2019. In another vital megacity of India i.e. Kolkata, the minimum value of UVI (11.13) has been registered in March, 2020 while the highest declining rate of UVI (3.12) has been identified in April, 2020 during the lockdown scenario. The notable fact is that during COVID-19 lockdown, the maximum reduction of UVI (13.18) has been estimated in Chennai in the month of April (2020) and the lowest index value of solar ultraviolet radiation (9.2) has been recorded in March over New Delhi (Table 3; Fig. 4; Supplementary Table S2). In this context, the negligible increase of UV index (0.24) in Chennai during May, 2020 compared with the same time period during pre-lockdown session is considered as an exceptional issue.

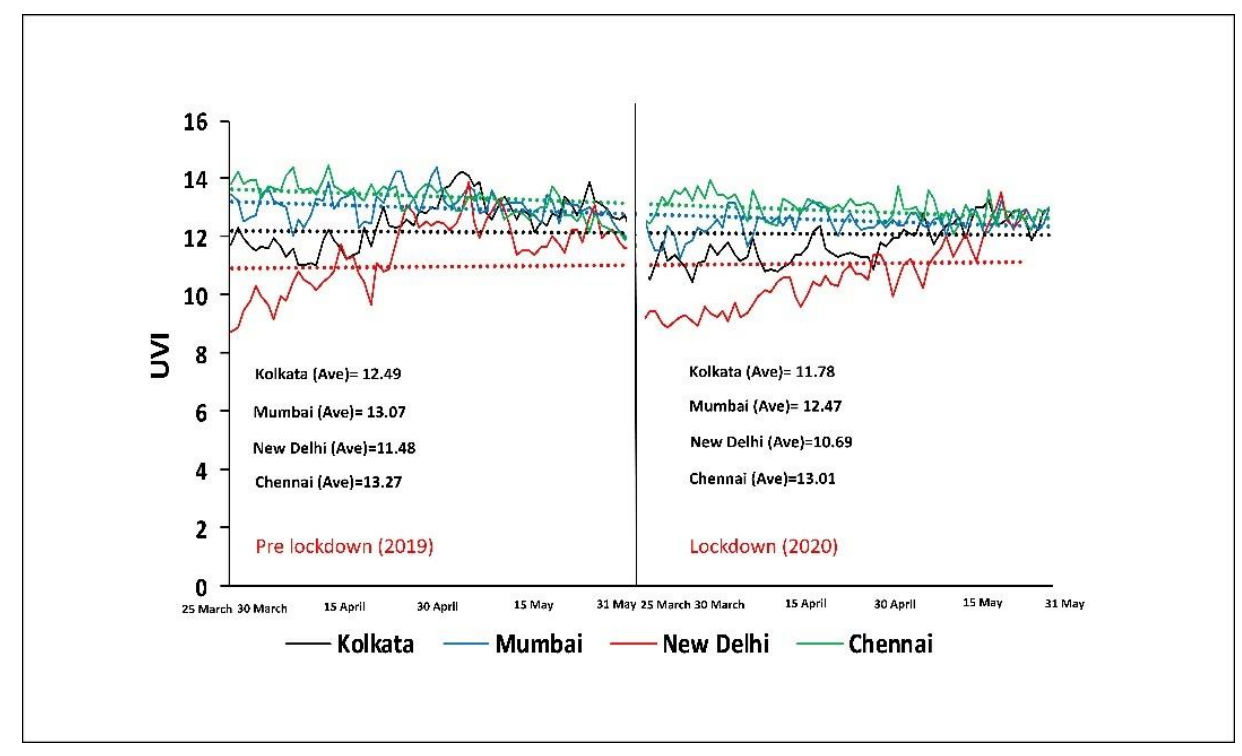

Fig. 4 The variation of UV index (UVI) through the sampling period $\left(25^{\text {th }}\right.$ March $-31^{\text {st }}$ May) during and pre lockdown period (2019-2020) 
Table 3 Monthly average intensity, percentage and changing share of ultraviolet index (UVI) during and pre lockdown phase in the major megacities of India

\begin{tabular}{|c|c|c|c|c|c|}
\hline $\begin{array}{l}\text { Name of the } \\
\text { megacities }\end{array}$ & Year & Month & UVI value & $\begin{array}{c}\text { UVI value } \\
(\%)\end{array}$ & $\begin{array}{c}\text { Share of } \\
\text { change }(\%)\end{array}$ \\
\hline \multirow[t]{6}{*}{ New Delhi } & 2019 & March & 9.55 & 50.93 & - \\
\hline & 2020 & & 9.2 & 49.07 & -1.86 \\
\hline & 2019 & April & 11.2 & 52.86 & - \\
\hline & 2020 & & 9.99 & 47.14 & -5.72 \\
\hline & 2019 & May & 12.19 & 51.03 & - \\
\hline & 2020 & & 11.7 & 48.97 & -2.06 \\
\hline \multirow[t]{6}{*}{ Mumbai } & 2019 & March & 13.12 & 52.42 & - \\
\hline & 2020 & & 11.91 & 47.58 & -4.84 \\
\hline & 2019 & April & 13.23 & 51.38 & - \\
\hline & 2020 & & 12.52 & 48.62 & -2.76 \\
\hline & 2019 & May & 12.9 & 50.65 & - \\
\hline & 2020 & & 12.57 & 49.35 & -1.3 \\
\hline \multirow[t]{6}{*}{ Kolkata } & 2019 & March & 11.79 & 51.44 & - \\
\hline & 2020 & & 11.13 & 48.56 & -2.88 \\
\hline & 2019 & April & 12.1 & 51.56 & - \\
\hline & 2020 & & 11.37 & 48.44 & -3.12 \\
\hline & 2019 & May & 13.03 & 51.38 & - \\
\hline & 2020 & & 12.33 & 48.62 & -2.76 \\
\hline \multirow[t]{6}{*}{ Chennai } & 2019 & March & 13.84 & 51.49 & - \\
\hline & 2020 & & 13.04 & 48.51 & -2.98 \\
\hline & 2019 & April & 13.64 & 50.86 & - \\
\hline & 2020 & & 13.18 & 49.14 & -1.72 \\
\hline & 2019 & May & 12.79 & 49.88 & - \\
\hline & 2020 & & 12.85 & 50.12 & +0.24 \\
\hline
\end{tabular}




\subsection{Assessment of surface $\mathrm{O}_{3}$ and UVI level using statistical techniques}

The correlation coefficient analysis (R) has been established the inter-relationship between tropospheric $\mathrm{O}_{3}$ and UV index over the four major megacities in India. In case of New Delhi, the correlation coefficient between surface $\mathrm{O}_{3}$ and UVI proves the strong negative relation during March of $2019\left(\mathrm{R}^{2}=0.9467\right)$ and $2020\left(\mathrm{R}^{2}=\right.$ 0.7381), April $2019\left(\mathrm{R}^{2}=0.7563\right)$ and May of $2019\left(\mathrm{R}^{2}=0.9346\right)$ and $2020\left(\mathrm{R}^{2}=0.9727\right)$ amidst pre-lockdown and lockdown period except the month of April, 2020 has experienced the slight negative correlation $\left(R^{2}=\right.$ 0.3596)(Fig.5). In case of Kolkata, the almost similar scenario has been depicted through coefficient correlation analysis. Here, the moderate negative correlation between the two variables has been exceptionally established in April during lockdown period $\left(\mathrm{R}^{2}=0.4436\right)$ while the statistical assessment represents the strong inverse relationship in March and May during and pre lockdown phase and the month of April, 2019 (Fig.6).

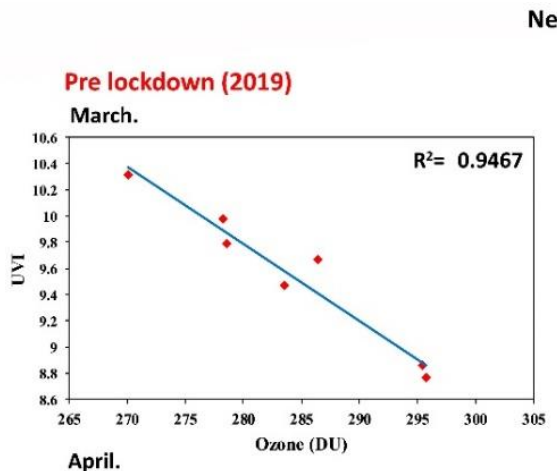

New Delhi

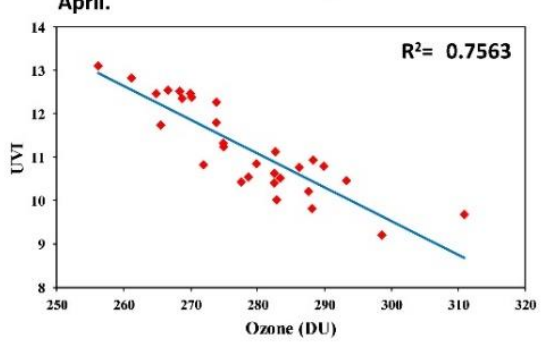

Lockdown (2020)

March.
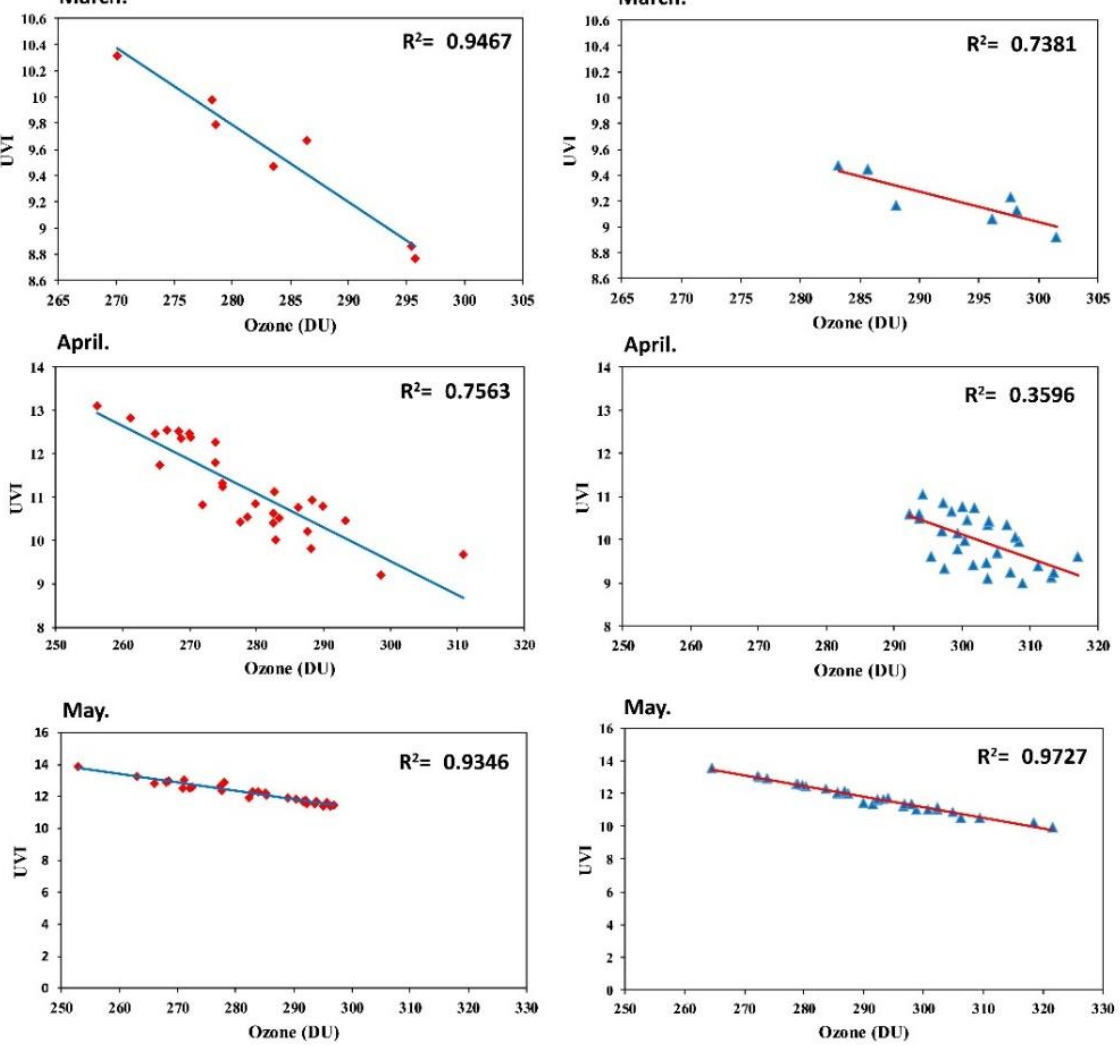

Fig. 5 Correlation between tropospheric $\mathrm{O}_{3}$ and $\mathrm{UV}$ index over New Delhi during the sampling period in the year 2019 and 2020. 


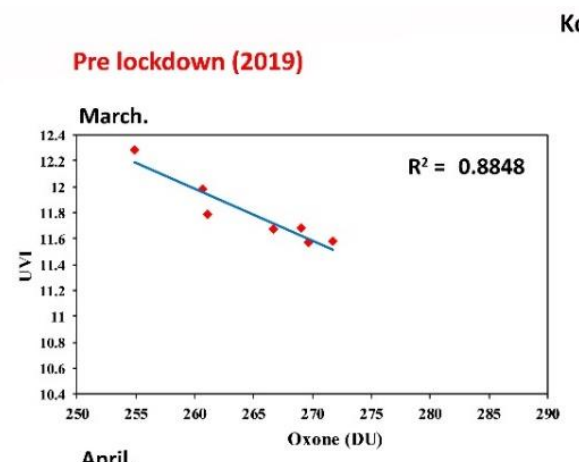

Kolkata
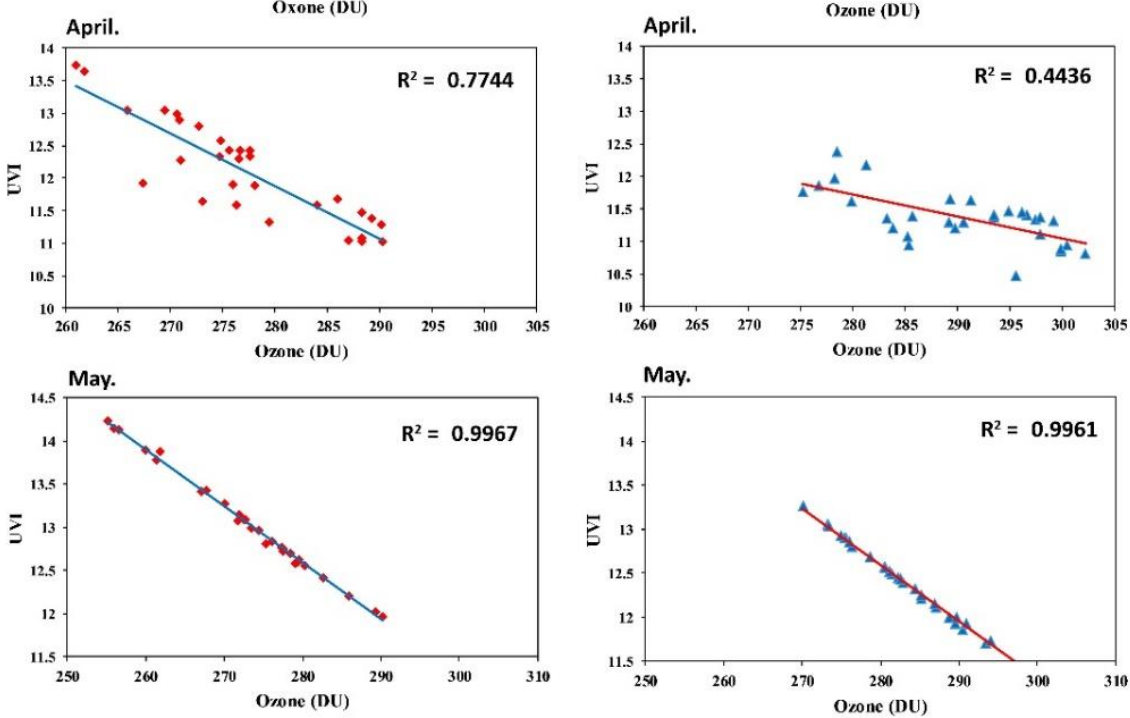

Fig. 6 Correlation between tropospheric $\mathrm{O}_{3}$ and UV index over Kolkata during the sampling period in the year 2019 and 2020

Moreover, Mumbai has also witnessed the strong inverse correlation between $\mathrm{O}_{3}$ concentration and UVI in March $\left(\mathrm{R}^{2}=8919\right.$ in $2019, \mathrm{R}^{2}=0.9595$ in 2020) and May $\left(\mathrm{R}^{2}=0.9961\right.$ in $2019, \mathrm{R}^{2}=0.9806$ in 2020) during lockdown and pre-lockdown where the moderate inverse relation between the two above-said criteria has been determined during April of $2019\left(R^{2}=0.5855\right)$ and $2020\left(R^{2}=0.6477\right)$ in this megacity (Fig.7). The study identifies that the correlation coefficient value $\left(\mathrm{R}^{2}\right)$ is varied within the range of 0.8069 to 0.9912 in Chennai during the sampling period amidst pre-lockdown and lockdown phase which demonstrates strongly negative correlation between tropospheric $\mathrm{O}_{3}$ accumulation and UV index over this important megacity in southern India (Fig.8). 


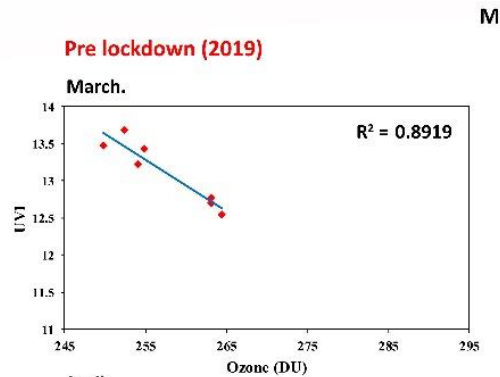

Mumbai

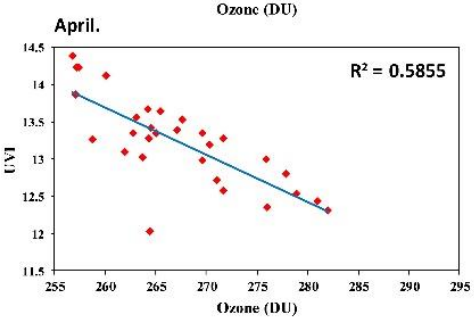

Lockdown (2020)
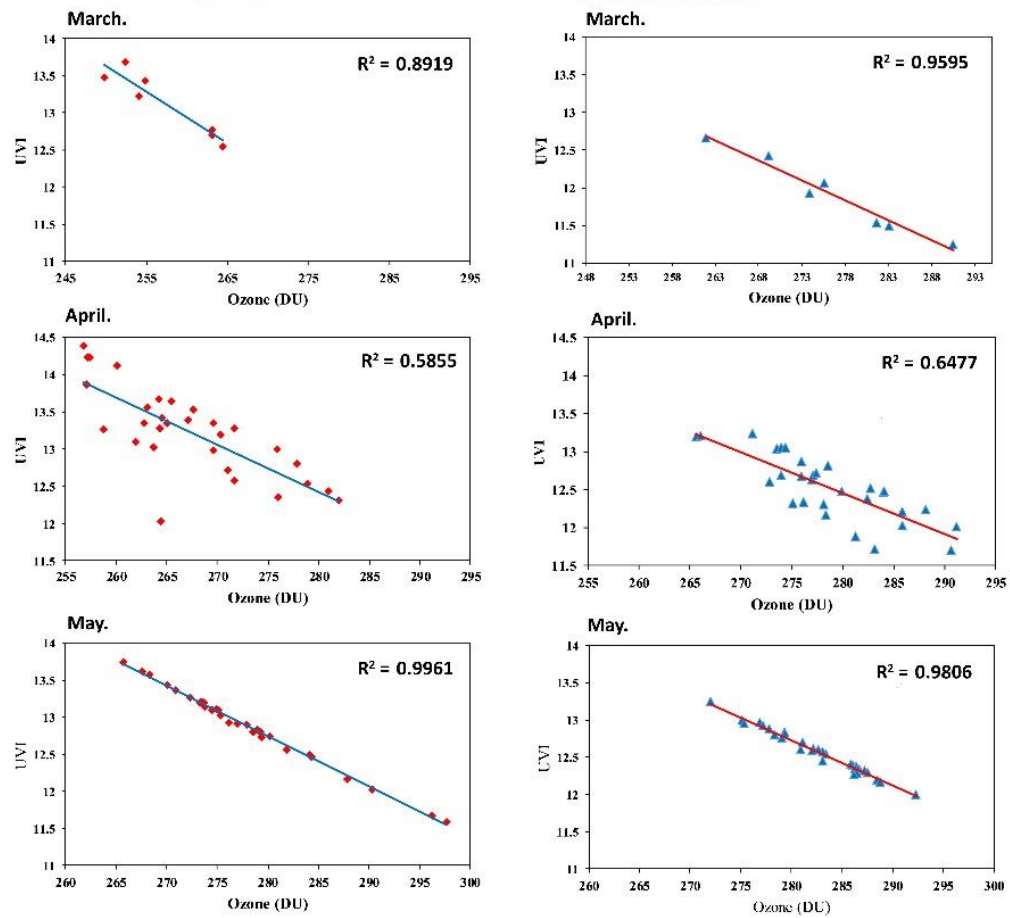

Fig. 7 Correlation between tropospheric $\mathrm{O}_{3}$ and $\mathrm{UV}$ index over Mumbai during the sampling period in the year 2019 and 2020

Chennai

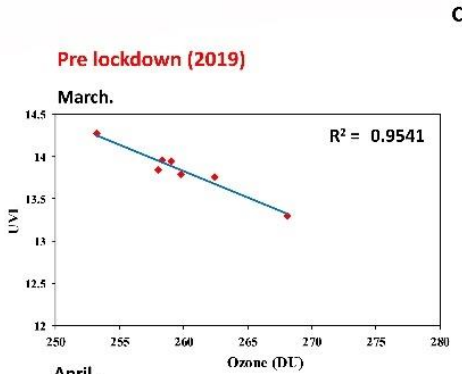

Lockdown (2020)
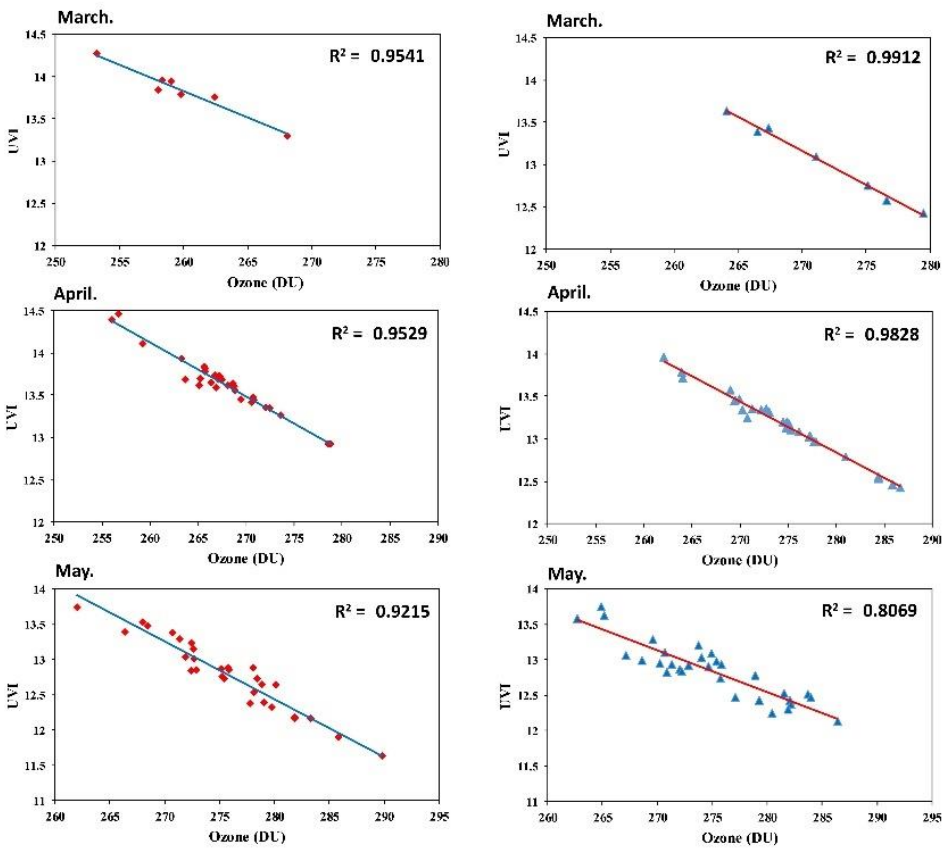

Fig. 8 Correlation between tropospheric $\mathrm{O}_{3}$ and $\mathrm{UV}$ index over Chennai during the sampling period in the year 2019 and 2020 
In the aspect of tropospheric $\mathrm{O}_{3}$ concentration, the value of mean and SE is 274.14 and 0.634 individually during 2019 while the value of mean and SE is 284.20 and 0.722 respectively with $t(271)=-11.932$ and $p<0.05$ during 2020 (Table 1; Supplementary Table S7). Therefore, it has been demonstrated that the concentration of tropospheric $\mathrm{O}_{3}$ is magnified amidst the lockdown session that is statistically tested or significant. Beside this, in case of UVI during 2019 the value of mean and standard error mean (SE) is 12.5789 and 0.06506 respectively whereas in the year of 2020 the value of mean and SE is 11.9913 and 0.06960 correspondingly with $t(271)=$ 11.661 and $\mathrm{p}<0.05$ (Table 1; Supplementary Table S7). Consequently, it has been verified that the intensity of UVI is declined during the lockdown period which has been statistically tested or significant. Thus, statistical analysis established that the lockdown system has a notable impact upon the modification of tropospheric $\mathrm{O}_{3}$ and UVI index. Similarly, the K-means clustering method has portrayed a prominent similarity in the context of ground-level $\mathrm{O}_{3}$ accumulation and UVI range over the selective megacities during lockdown scenario in 2020.On the other side, during the pre-lockdown session in the year 2019 the concentration status of the two parameters over the four megacities illustrates the completely distinct scenario. The K-means cluster algorithms have grouped New Delhi, Mumbai, Kolkata and Chennai in two separate clusters individually for lockdown and pre-lockdown phase (Supplementary Table S8).

The correlation matrix has been used to represent the correlation of the UVI and $\mathrm{O}_{3}$ with the climatic variables (temperature, wind speed, gust, relative humidity, cloud and air pressure) over the selective megacities of India during and pre lockdown phase (Fig. 9; Fig. 10). During the lockdown period (2020), UVI has a positive correlation with the climatic factors i.e. wind speed, gust and relative humidity in most of the megacities whereas only New Delhi has a slightly negative correlation between UVI and relative humidity. Air pressure has a negative correlation with UVI but there is an exception in case of Chennai during lockdown period (2020). During lock down period most of the megacities has a positive correlation between temperature and UVI but in case of Chennai there has a slightly negative correlation between UVI and temperature. Moreover, the distinct correlation between climatic variables and $\mathrm{O}_{3}$ has been notified over the four megacities during lockdown period (2020). In the aspect of Chennai and Mumbai, a slightly positive correlation has been identified among $\mathrm{O}_{3}$ and temperature, wind speed, gust and cloud; whereas a negative interrelationship among $\mathrm{O}_{3}$ and temperature, wind speed and gust have been observed over Kolkata and New Delhi amidst the lockdown phase. During the pre-lockdown period (2019), a different trend of interrelation has been witnessed among the climatic factors and UVI and $\mathrm{O}_{3}$. A positive correlation between climatic factors (except air pressure) and UVI over Kolkata has been noticed amidst prelockdown period. Alongside, there is no correlation between few climatic factors and $\mathrm{O}_{3}$ while slightly negative 
correlation has been identified between other climatic factors and $\mathrm{O}_{3}$ over Kolkata during the same time frame. Relative humidity and air pressure have established a negative relationship with UVI and a slightly positive relationship between $\mathrm{O}_{3}$ and climatic factors have been observed over New Delhi. Over Mumbai no correlation along with slightly negative correlation has been seen between UVI and climatic factors whereas relative humidity and wind speed have a positive relation with $\mathrm{O}_{3}$ during pre-lockdown period.
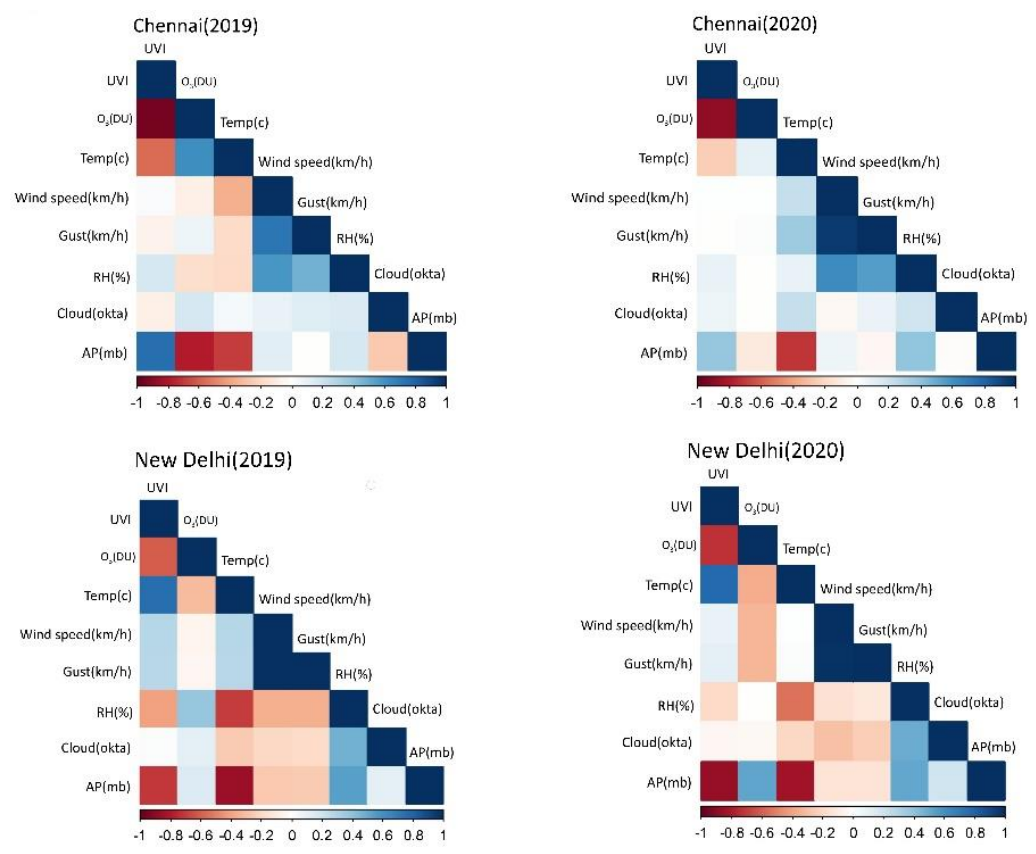

Fig. 9 Correlation of UVI and $\mathrm{O}_{3}$ with climatological factors over Chennai and New Delhi during (2020) and pre-lockdown (2019) phase 

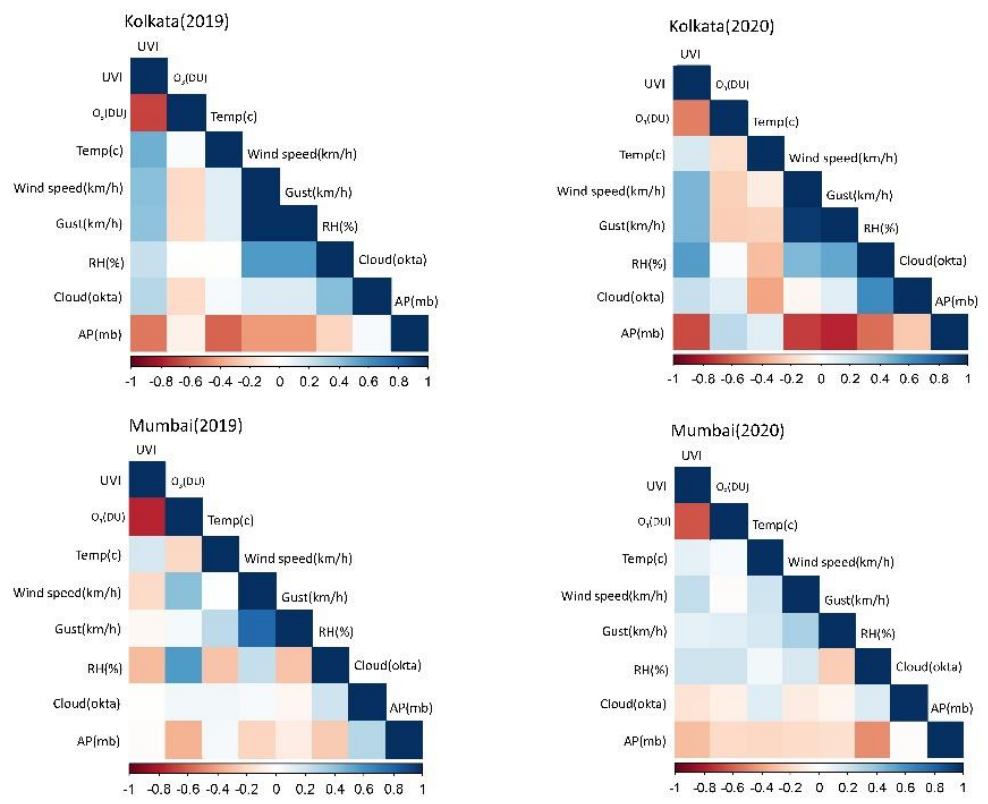

Fig. 10 Correlation of UVI and $\mathrm{O3}$ with climatological factors over Kolkata and Mumbai during (2020) and pre-lockdown (2019) phase

\section{Discussions}

The solar spectrum is characterized with $100 \mathrm{~nm}$ to $400 \mathrm{~nm}$ wavelengths and it is demarcated as ultraviolet radiation (Hu et al. 2007). The unprecedented exaggeration of UV radiation penetration in the earth surface is an issue of serious concern as the UV ray exerts dreadful effects on every sphere of natural environment. The range of UV index is accentuated with the increase of altitude while the diurnal maximum concentration of UV ray is recorded at noon due to the perpendicular angle of solar radiation. Seasonally, the highest intensity of UV ray is measured during spring and summer whereas the minimal presence of UV radiation is registered during winter. The wavelength of UV ray which invades to the surface of the earth is varied within $290 \mathrm{~nm}$ to $400 \mathrm{~nm}$ (Chadysiene et al. 2005). The entire UV-A radiation reaches to the earth's surface as there is no incident of UVA absorption by atmospheric ozone (Tan et al. 2018) while UV- C is wholly engrossed by ozone and oxygen in the upper and middle portion of the atmosphere (Chandra and Mcpeters 1994). Stratospheric ozone can absorb UV-B very effectively though about 10\% radiation falls upon the earth's surface (Madronich et al. 1998; Hu et al. 2007). In the current study, it must be noteworthy that in the lower part of the atmosphere with the higher intensity of ozone concentration can oscillate the range of UV index over the tropical region like India. 
During the COVID-19 lockdown period, the strengthening of tropospheric ozone over New Delhi, Mumbai, Kolkata and Chennai has been instigated to drop the UV index compared with the preceding year, 2019. Commonly, the natural presence of surface $\mathrm{O}_{3}$ is confined around 0.04 parts per million (ppm) which is not injurious for health safety of human being (Bera et al. 2020). The fact is notable that higher accumulation of $\mathrm{O}_{3}$ during the lockdown phase over the lower atmosphere of four megacities does not exceed the permissible limit. The excess amount of $\mathrm{O}_{3}$ has remarkably contributed to trap the harmful UV radiation which has lowered the UVI in these worst polluted megacities of India. During lockdown, the partial halting of industrial activities, vehicle movement, constructional works, burning of fuels markedly dwindles the concentration of lethal air pollutants like $\mathrm{NO}_{2}, \mathrm{NO}, \mathrm{CO}$ and $\mathrm{VOC}$ over the atmosphere of these tremendously polluted cities (CPCB 2020; Sharma et al. 2020). Different anthropogenic activities mainly burning of fossil fuel, heating activities in industrial furnace, diesel combustion in engine augment the accumulation of air pollutants like nitrogen oxides $\left(\mathrm{NO}_{\mathrm{x}}\right)$ over extremely polluted cities (Bark et al. 2005; Carslaw2005; Carslaw and Beevers 2004a, b). Generally, the concentration of $\mathrm{CO}$ and $\mathrm{NO}_{2}$ is significantly dropped in the major megacities of India due to the restricted industrial and transport activities during the quarantine phase compared with the pre-lockdown phase (CPCB 2020; Bera et al. 2020). In the atmosphere, around $90 \%$ of nitrogen is released as nitric oxide (NO) while $<10 \%$ nitrogen is produced in the form of nitrogen dioxide $\left(\mathrm{NO}_{2}\right)$. The existence of surface $\mathrm{O}_{3}$ is dependent on the share of production and annihilation of $\mathrm{NO}$ as $\mathrm{O}_{3}$ has the competency to speedily react with nitric oxide (Vellingiri et al. 2015). The consumption of $\mathrm{O}_{3}$ is reduced due to curtail of $\mathrm{NO}$ emission which improves the accumulation status of $\mathrm{O}_{3}$ (Andrade et al. 2017; Tobias et al. 2020). Meanwhile, the prominent reduction of $\mathrm{NO}_{\mathrm{x}}$ during the lockdown period brings the titration impact to $\mathrm{O}_{3}$ and this mechanism helps to revitalize the ozone concentration level ( $\mathbf{L i}$ et al. 2020). Alongside, another participating component of surface $\mathrm{O}_{3}$ generation i.e. $\mathrm{VOC}$ is also curtailed in the lower atmosphere over Indian cities due to the closure of its human-induced sources like yield of petroleum and natural gas (Gilman et al. 2013; Petron et al. 2012), transport activities (Russo et al. 2010), wood combustion (Kansal2009), industrial production (Gilman et al. 2009) during lockdown session (CPCB 2020). As the abovementioned pollutants $\left(\mathrm{NO}_{\mathrm{x}}, \mathrm{VOC}, \mathrm{CO}\right)$ are regarded as the chief responsible ingredients in formation process of surface $\mathrm{O}_{3}$ and their lesser existence promotes to rejuvenate $\mathrm{O}_{3}$ level in the lower atmosphere over the four selective megacities of India during the lockdown period in comparison with pre-lockdown state. In this context, the fact must be mentioned that the changing pattern of various meteorological elements like temperature, pressure, relative humidity, wind speed and direction can modify the creation and destruction process of surface $\mathrm{O}_{3}$ (Dueñas et al. 2002; Elminir2005; Satsangi et al. 2004).The meteorological factors like relative humidity, wind speed 
and wind direction have diverse effects on ozone concentration at the ground level of the atmosphere. Data analysis showed that ground level ozone concentrations expand with the increase of temperature; though, it is not significantly connected to relative air humidity (Supplementary Table S3, S4, S5, S6). Nevertheless, the wind direction has the great influence on the deviation of ozone concentrations.

That's why sometimes ground-level $\mathrm{O}_{3}$ may be slightly decreased instead of the steady decline of $\mathrm{NO}_{x}, \mathrm{VOC}, \mathrm{CO}$ in the lower atmosphere and this exceptional phenomenon has been recorded over Chennai in the month of May during lockdown. On the other side, the notable fact is that the UVI over the four major megacities in India is fluctuated between the range of 9 and 13 during the lockdown phase in 2020 which highlights very high to extreme risk of damage from uncovered solar exposure. But the intensity of UV radiation coming to the earth surface is markedly dropped as a consequence of ground-level $\mathrm{O}_{3}$ amplification over the selective megacities amidst lockdown period in comparison with pre-lockdown year which is a momentous trademark for environmental safety.

\section{Conclusion}

In general, the concentration of UV ray is persisted comparatively higher over the tropical regions except the winter season. The matter is mostly remarkable that amidst the unusual and unpleasant situation during COVID19 lockdown, the accumulation of various air pollutants such as $\mathrm{NO}_{2}, \mathrm{NO}, \mathrm{CO}, \mathrm{SO}_{2}, \mathrm{PM}_{10}, \mathrm{PM}_{2.5}$ and $\mathrm{O}_{3}$ have been considerably altered due to the temporary pausing of industrial function, transportation activities and several man-made actions and this air quality modifications assist to eradicate the fatal impurities in the atmospheric arena. The study demonstrates that satisfactory changes in air quality standard accentuate the surface ozone concentration within the desirable limit which influences to cut down the UV index to some extent in different corners of India during lockdown phase. Although the excessive amount of ground-level ozone is undoubtedly hazardous for living organisms including human-being and it is labelled as "bad ozone". But it plays crucial role to diminish UV index level and it is highly appreciable for nourishing environmental health if the $\mathrm{O}_{3}$ concentration is confined within the permissible limit. In this context, it must be opined that the lockdown system is definitely accountable for the massive devastation in global economic and socio-cultural aspects; however the glimpse of total environmental restoration has been brightened specifically during this unfamiliar quarantine session. Worldwide the fact is highly admitted that the excessively populous as well as worst polluted cities and countries including Indian megacities momentarily reclaim their environmental transparencies and ecological stability during the lockdown period. Subsequently, the environmentalists, scientists and researchers have opined to 
introduce the partial lockdown as the sacred blessings towards every spheres of environment. So, it must be specified that the efficacy of short-term lockdown system should be acknowledged for ensuring the long-term sustainable environmental management as well as ecological renovation in the acutely polluted megacities of India.

\section{Acknowledgements}

The authors would like to acknowledgeNASA Earth Observatory (NEO) hub.Simultaneously, the authors are also grateful to Tropospheric Emission Monitoring Internet Service for providing necessary data related with the UVI and tropospheric $\mathrm{O}_{3}$ concentration over the major megacities of India (New Delhi, Mumbai, Kolkata, and Chennai) during the sampling period. We also express our sincere gratitude to World Weather Online platform for obtaining relevant daily climatic data over the four megacities during and pre-lockdown period.

\section{Declarations}

\section{Ethics approval and consent to participate}

All authors approve to publish the fundamental research work and there is no ethical conflict.

Consent for publication All authors read the manuscript and agreed to publication.

Availability of data and material Not applicable.

\section{Competing interests}

The authors declare that they have no known competing financial interests or personal relationships that could have appeared to influence the work reported in this paper.

Funding Not applicable.

Authors' Contributions Biswajit Bera: Conceptualization, Methodology, Formal analysis, Writing - original draft, Writing - review \& editing, Visualization. Sumana Bhattacharjee: Conceptualization, Supervision, Writing - review \& editing. Pravat Kumar Shit: Supervision, Formal analysis, Writing - review \& editing. Nairita Sengupta: Writing - original draft, Formal analysis. SoumikSaha: Formal analysis,Visualization.All authors contributed to the study and approved the final manuscript. 
Acknowledgement Not applicable.

\section{References}

Andrade MF, Kumar P, Freitas ED, Ynoue RY, Martins J, Martins LD, Nogueira T, Perez-Martinez P, Miranda RM, Albuquerque T, Gonçalves FLT, Oyama B, Zhang Y (2017) Air quality in the megacity of São Paulo: evolution over the last 30 years and future perspectives. Atmos Environ 159:66-82. https://doi.org/10.1016/j.atmosenv.2017.03.051.

Barck C, Lundahl J, Hallden G, Bylin G (2005) Brief exposures to $\mathrm{NO}_{2}$ augment the allergic inflammation in asthmatics. Environ Res 97:58-66. https://doi.org/10.1016/j.envres.2004.02.009.

Bates D (1994) The effects of ozone on plants and people. In: Calvert J (Ed), Chemistry of the Atmosphere: Its Impact on Global Change. Blackwell Scientific Publications pp. 239-244.

Beig G, Gunthe S, Jadhav DB (2007) Simultaneous measurements of ozone and its precursors on a diurnal scale at a semi urban site in India. J Atmos Chem 57:239-253. https://doi.org/10.1007/s10874-007-9068-8.

Bera B, Bhattacharjee S, Ghosh A et al (2019) Dynamic of channel potholes on Precambrian geological sites of Chhota Nagpur plateau, Indian peninsula: applying fluvio-hydrological and geospatial techniques. SN Appl Sci 1:494. https://doi.org/10.1007/s42452-019-0516-2.

Bera B, Bhattacharjee S, Shit PK, Sengupta N, Saha S (2020) Significant impacts of COVID-19 lockdown on urban air pollution in Kolkata (India) and amelioration of environmental health. Environment, Development and Sustainability. https://doi.org/10.1007/s10668-020-00898-5.

Brasseur G, Solomon S (1986) Aeronomy of the middle atmosphere. D Reidel Publishing Company.

Carslaw DC (2005) Evidence of an increasing $\mathrm{NO}_{2} / \mathrm{NO}_{\mathrm{x}}$ emissions ratio from road traffic emissions. Atmos Environ 39:4793-4802. https://doi.org/10.1016/j.atmosenv.2005.06.023.

Carslaw DC, Beevers SD (2004a) Investigating the potential importance of primary $\mathrm{NO}_{2}$ emissions in a street canyon. Atmos Environ 38:3585-3594. https://doi.org/10.1016/j.atmosenv.2004.03.041.

Carslaw DC, Beevers SD (2004b) New directions: Should road vehicle emissions legislation consider primary $\mathrm{NO}_{2}$ ? Atmos Environ 38:1233-1234. https://doi.org/10.1016/j.atmosenv.2003.12.008. 
Central Pollution Control Board (CPCB) (2020) Impact of lockdown (25th March to 15th April) on air quality. Ministry of Environment, Forest and Climate Change, Govt. of India, Delhi pp. 1-62. https://cpcb.nic.in/latest-cpcb.php.

Chadyšiene R, Girgždiene R, Girgždys A (2005) Ultraviolet radiation and ground-level ozone variation in Lithuania. Journal of Environmental Engineering and Landscape Management 13:31-36. https://doi.org/10.1080/16486897.2005.9636843.

Chakraborty I, Maity P (2020) COVID-19 outbreak: Migration, effects on society, global environment and prevention. Sci Total Environ 728:1-7. https://doi.org/10.1016/j.scitotenv.2020.138882.

Chandra S, McPeters RD (1994) The solar cycle variation of ozone in the stratosphere inferred from Nimbus 7 and NOAA 11 satellites. J Geophys Res 99:20665-20671. https://doi.org/10.1029/94JD02010.

covid19india.org (2020) Coronavirus in India. https://www.covid19india.org/.

Dueñas C, Fernández MC, Cañete S, Carretero J, Liger E (2002) Assessment of Ozone Variations and Meteorological Effects in an Urban Area in the Mediterranean Coast. Sci Total Environ 299:97-113. http://dx.doi.org/10.1016/S0048-9697(02)00251-6.

Dutheil F, Baker SJ, Navel V (2020) COVID-19 as a factor influencing air pollution? Environ Pollut. https://doi.org/10.1016/j.envpol.2020.114466.

Elminir HK (2005) Dependence of Urban Air Pollutants on Meteorology. Sci Total Environ 350:225-237. http://dx.doi.org/10.1016/j.scitotenv.2005.01.043.

Finlayson-Pitts B, Pitts Jr J (1997) Tropospheric air pollution: ozone, airborne toxics, polycyclic aromatic hydrocarbons, and particles. Science 276:1045-1051. https://doi.org/10.1126/science.276.5315.1045.

Fioletov V, Kerr J, Fergusson A (2010) The UV Index: Definition, Distribution and Factors Affecting It. Canadian journal of public health, Revue canadienne de santépublique. DOI: 10.1016/j.atmosres.2012.01.005.

Fishman J, Crutzen PJ (1977) A numerical study of tropospheric photochemistry using a one-dimensional model. J Geophys Res 82:5897-5906. https://doi.org/10.1029/JC082i037p05897.

Fishman J, Crutzen PJ (1978) The origin of ozone in troposphere. Nature 274:855-858. https://doi.org/10.1038/274855a0.

Garcia MA, Sanchez ML, Perez IA, de Torre B (2005) Ground level ozone concentrations at a rural location in northern Spain. Sci Total Environ 348:135-150. https://doi.org/10.1016/j.scitotenv.2004.12.049. 
Gautam S (2020) COVID-19: air pollution remains low as people stay at home. Air Quality, Atmosphere \& Health. https://doi.org/10.1007/s11869-020-00842-6.

Ghude SD, Jain SL, Arya BC, Beig G, Ahammed YN, Kumar A et al (2008) Ozone in ambient air at a tropical megacity, Delhi: characteristics, trends and cumulative ozone exposure indices. J Atmos Chem 60:237252. https://doi.org/10.1007/s10874-009-9119-4.

Gies P, van Deventer E, Green AC, Sinclair C, Tinker R (2018) Review of the global solar UV index 2015 workshop report. Health Phys 114:84-90. https://dx.doi.org/10.1097\%2FHP.0000000000000742.

Gilman JB, Kuster WC, Goldan PD, Herndon SC, Zahniser MS, Tucker SC, Brewer WA, Lerner BM, Williams EJ, Harley RA et al (2009) Measurements of volatile organic compounds during the 2006 TexAQS/GoMACCS campaign: Industrial influences, regional characteristics, and diurnal dependencies of the OH reactivity. J Geophys Res Atmos 114. https://doi.org/10.1029/2008JD011525.

Gilman JB, Lerner BM, Kuster WC, de Gouw JA (2013) Source signature of volatile organic compounds from oil and natural gas operations in northeastern Colorado. Environ Sci Technol 47:1297-1305. https://doi.org/10.1021/es304119a.

Hogsett WE, Weber JE, Tingey DT, Herstrom AA, Lee EH, Laurence JA (1997) An approach for characterizing tropospheric ozone risk to forests. Environ Manag 21:105-120.

Huang C, Wang Y, Li X, Ren L, Zhao J, Hu Y et al (2020) Clinical features of patients infected with 2019 novel coronavirus in Wuhan, China. Lancet 395:497-506. https://doi.org/10.1016/S0140-6736(20)30183-5.

Huang X, Ding A, Gao J, Zheng B, Zhou D, Qi X, Tang R, Ren C, Nie W, Chi X, Wang J (2020) Enhanced Secondary Pollution Offset Reduction of Primary Emissions during COVID-19 Lockdown in China. EarthArXiv. https://doi.org/10.31223/osf.io/hvuzy.

Hu B, Wang Y, Liu G (2007) Ultraviolet radiation spatio-temporal characteristics derived from the ground-based measurements taken in China. Atmos Environ 41:5707-5718. https://doi.org/10.1016/j.atmosenv.2007.02.044.

Jain SL, Arya BC, Kumar A, Ghude SD, Kulkarni PS (2005) Observational study of surface ozone at New Delhi, India. Int J Remote Sens 26:3515-3524. https://doi.org/10.1080/01431160500076616.

Jerrett M, Burnett RT, Pope CA, Ito K, Thurston G, Krewski D et al (2009) Long-term ozone exposure and mortality. New Engl J Med 360:1085-1095. https://doi.org/10.1056/nejmoa0803894. 
Jribi S, Ismai HB, Doggui D, Debbabi K (2020) COVID-19 virus outbreak lockdown: What impacts on household food wastage? Environment, Development and Sustainability 22:3939-3955. https://dx.doi.org/10.1007\%2Fs10668-020-00740-y.

Kansal A (2009) Sources and reactivity of NMHCs and VOCs in the atmosphere: a review. J Hazard Mater 166:17-26. https://doi.org/10.1016/j.jhazmat.2008.11.048.

Lal S, Naja M, Subbaraya BH (2000) Seasonal variations in surface ozone and its precursors over an urban site in India. Atmos Environ 34:2713-2724. https://doi.org/10.1016/S1352-2310(99)00510-5.

Lau H, Khosrawipour V, Kocbach P, Mikolajczyk A, Schubert J, Bania J, Khosrawipour T (2020) The positive impact of lockdown in Wuhan on containing the COVID-19 outbreak in China. Journal of Travel Medicine 37:1-14. https://doi.org/10.1093/jtm/taaa037.

Li L, Li Q, Huang L, Wang Q, Zhu A, Xu J, Liu Z, Li H, Shi L, Li R, Azari M, Wang Y, Zhang X, Liu Z, Zhu Y, Zhang K, Xue S, Ooi MCG, Zhang D, Chan A (2020) Air quality changes during the COVID-19 lockdown over the Yangtze River Delta Region: An insight into the impact of human activity pattern changes on air pollution variation. Sci Total Environ 732:1-11. https://doi.org/10.1016/j.scitotenv.2020.139282.

Madronich S, McKenzie RL, Bjorn LO, Caldwell MM (1998) Changes in biologically active ultraviolet radiation reaching the Earth's surface. Journal of Photochemistry and Photobiology B: Biology 46:5-19. https://doi.org/10.1016/S1011-1344(98)00182-1.

Meves A, Repacholi MH, Rehfuess EA (2003) Global Solar UV Index: a physician's tool for fighting the skin cancer epidemic. Int J Dermatol 42:846-849. https://doi.org/10.1046/j.1365-4362.2003.02087.x.

Muhmmad S, Long X, Salman M (2020) COVID-19 pandemic and environmental pollution: A blessing in disguise? Sci Total Environ 728:1-5. https://doi.org/10.1016/j.scitotenv.2020.138820.

Nair PR, Chand D, Lal S, Modh KS, Naja M, Parameswaran K et al (2002) Temporal variations in surface ozone at Thumba $\left(8.6^{\circ} \mathrm{N}, 77^{\circ} \mathrm{E}\right)$ - a tropical coastal site in India. Atmos Environ 36:603- 610. https://doi.org/10.1016/S1352-2310(01)00527-1.

Naja M, Lal S (2002) Surface ozone and precursor gases at Gadanki (13.5 $\left.{ }^{\circ} \mathrm{N}, 79.2^{\circ} \mathrm{E}\right)$, a tropical rural site in India. J Geophys Res-Atmos 107:1-13. https://doi.org/10.1029/2001JD000357.

Nakada LYK, Urban RC (2020) COVID-19 pandemic: Impacts on the air quality during the partial lockdown in São Paulo state, Brazil. Sci Total Environ 730:1-5. https://doi.org/10.1016/j.scitotenv.2020.139087. 
NASA Earth Observatory Hub (NEO) (2020). https://neo.sci.gsfc.nasa.gov/.

Nishanth T, Praseed KM, Kumar MKS, Valsaraj KT (2014) Influence of ozone precursors and PM $_{10}$ on the variation of surface $\mathrm{O}_{3}$ over Kannur, India. Atmos Res 138:112-124. https://doi.org/10.1016/j.atmosres.2013.10.022.

Petron G, Frost G, Miller BR, Hirsch AI, Montzka SA, Karion A, Trainer M, Sweeney C, Andrews AE et al (2012) Hydrocarbon emissions characterization in the Colorado Front Range: a pilot study. J Geophys Res Atmos 117. https://doi.org/10.1029/2011JD016360.

Russo RS, Zhou Y, White ML, Mao H, Talbot R, Sive BC (2010) Multi-year (2004-2008) record of nonmethane hydrocarbons and halocarbons in New England: seasonal variations and regional sources. Atmos Chem Phys 10:4909-4929. https://doi.org/10.5194/acp-10-4909-2010.

Satsangi GS, Lakhani A, Kulshrestha PR, Taneja A (2004) Seasonal and Diurnal Variation of Surface Ozone and a Preliminary Analysis of Exceedance of Its Critical Levels at a Semi-Arid Site in India. J Atmos Chem 47:271-286. https://doi.org/10.1023/B:JOCH.0000021156.04126.3b.

Sharma S, Zhang M, Gao J, Zhang H, Kota SH (2020) Effect of restricted emissions during COVID-19 on air quality in India. Sci Total Environ 728:1-8. https://doi.org/10.1016/j.scitotenv.2020.138878.

Tan KC, Lim HS, Jafri MZM (2018) Study on solar ultraviolet erythemal dose distribution over Peninsular Malaysia using Ozone Monitoring Instrument. The Egyptian Journal of Remote Sensing and Space Sciences 21:105-110. http://dx.doi.org/10.1016/j.ejrs.2017.01.001.

Tobías A, Carnerero C, Reche C, Massagué J, Via M, Minguillón MC, Alastuey A, Querol X (2020) Changes in air quality during the lockdown in Barcelona (Spain) one month into the SARS-CoV-2 epidemic. Sci Total Environ 726:1-4. https://doi.org/10.1016/j.scitotenv.2020.138540.

Tropospheric Emission Monitoring Internet Service (TEMIS) (2020). http://www.temis.nl/index.php.

Varshney CK, Aggarwal M (1992) Ozone pollution in the urban atmosphere of Delhi. Atmos Environ 26:291294. https://doi.org/10.1016/0957-1272(92)90004-C.

Vellingiri K, Kim KH, Jeon JY, Brown RJC (2015) Changes in $\mathrm{NO}_{x}$ and $\mathrm{O}_{3}$ concentrations over a decade at a central urban area of Seoul, Korea. Atmos Environ 112:116-125. http://dx.doi.org/10.1016/j.atmosenv.2015.04.032.

Wang XK, Lu WZ, Wang WJ, Leung AYT (2003) A study of ozone variation trend within area of affecting human health in Hong Kong. Chemosphere 52:1405-1410. https://doi.org/10.1016/S0045-6535(03)00476-4. 
Wee SL, McNeil Jr DG, Hernandez JC (2020) W.H.O declares global emergency as Wuhan coronavirus spreads. The New York times. https://www.nytimes.com/2020/01/30/health/coronavirus-world-healthorganization.html.

WHO (2020a) Statement on the Second Meeting of the International Health Regulations (2005) Emergency Committee Regarding the Outbreak of Novel Coronavirus (2019-nCoV). World Health Organization (WHO) (Press release). https://www.who.int/news-room/detail/23-01-2020-statement-on-the-meetingof-the-international-health-regulations-(2005)-emergency-committee-regarding-the-outbreak-of-novelcoronavirus-(2019-ncov).

WHO (2020b) WHO director-General's opening remarks at the media briefing on COVID19 - 11 March 2020. https://www.who.int/dg/speeches/detail/who-director-general-s-opening-remarks-at-the-mediabriefing-on-covid-19---11-march-2020.

World Health Organization, World Meteorological Organization, United Nations Environment Programme \& International Commission on Non-Ionizing Radiation Protection (2002) Global solar UV index: a practical guide. World Health Organization, Geneva. http://www.who.int/iris/handle/10665/42459.

World Weather Online (2020). https://www.worldweatheronline.com/.

Zhang X, Wang H, Che HZ, Tan SC, Shi GY, Yao XP (2020) The impact of aerosol on MODIS cloud detection and property retrieval in seriously polluted East China. Sci Total Environ 711:134634. https://doi.org/10.1016/j.scitotenv.2019.134634.

Zhou P, Yang XL, Wang XG, Hu B, Zhang L, Zhang W et al (2020) Discovery of a novel coronavirus associated with the recent pneumonia outbreak in humans and its potential bat origin. bioRxiv. https://doi.org/10.1101/2020.01.22.914952.

Zhu N, Zhang D, Wang W, Li X, Yang B, Song J et al (2020) A novel coronavirus from patients with pneumonia in China, 2019. N Engl J Med 382:727-733. https://doi.org/10.1056/NEJMoa2001017. 


\section{Figures}
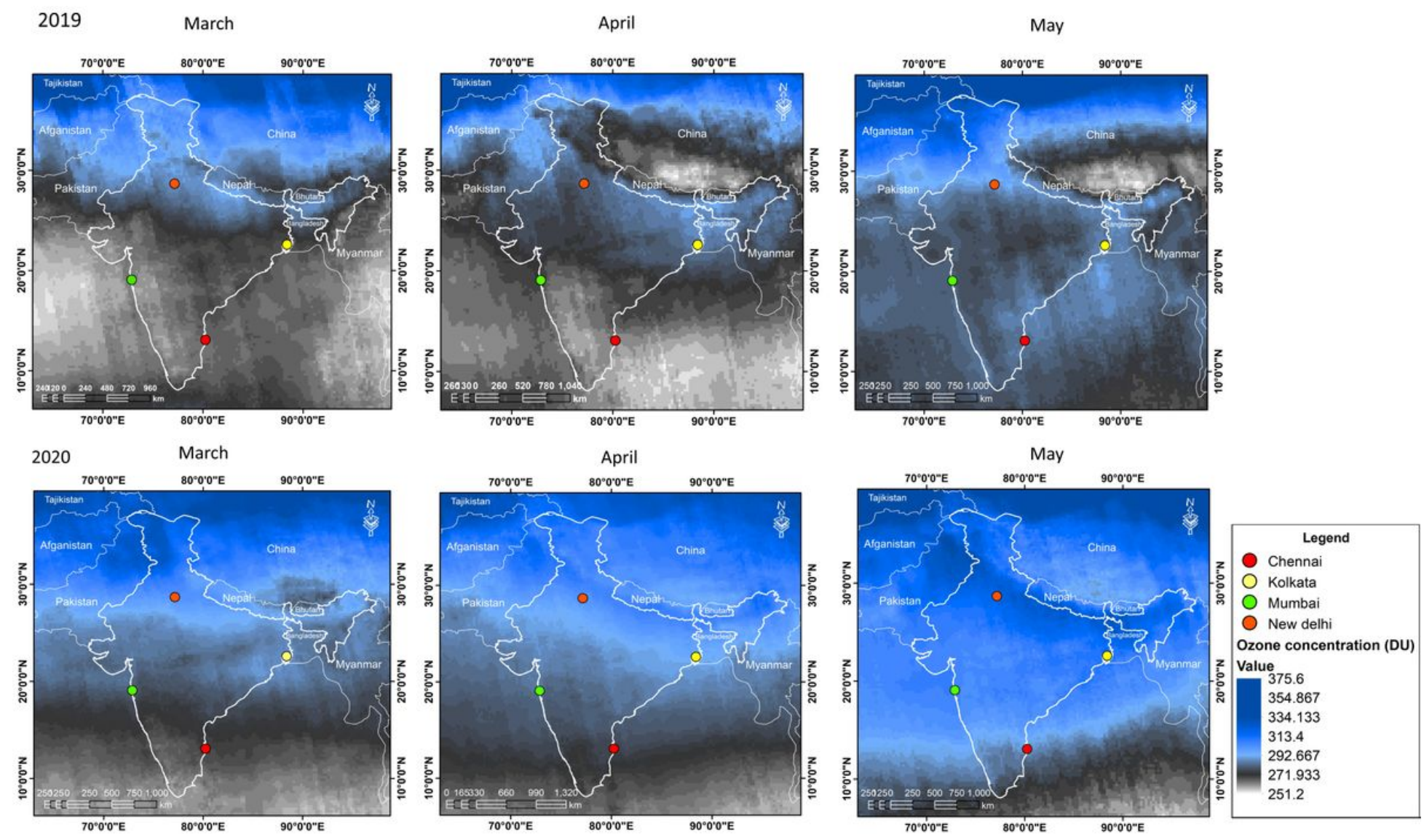

\section{Figure 1}

The fluctuation of tropospheric ozone concentration over the megacities of India during 2019-2020 (25th March - 31st May). Note: The designations employed and the presentation of the material on this map do not imply the expression of any opinion whatsoever on the part of Research Square concerning the legal status of any country, territory, city or area o bbnhjr of its authorities, or concerning the delimitation of its frontiers or boundaries. This map has been provided by the authors. 


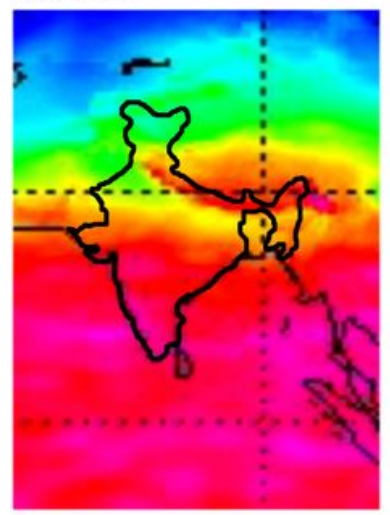

30-3-2020

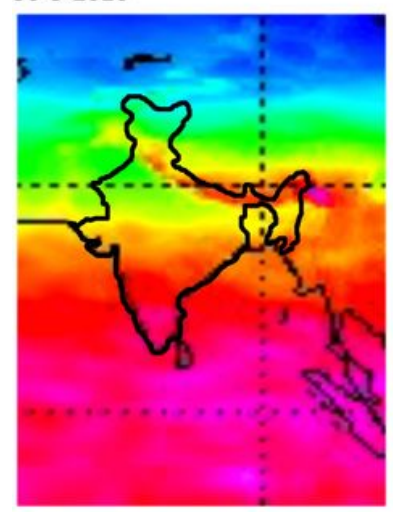

15-4-2019

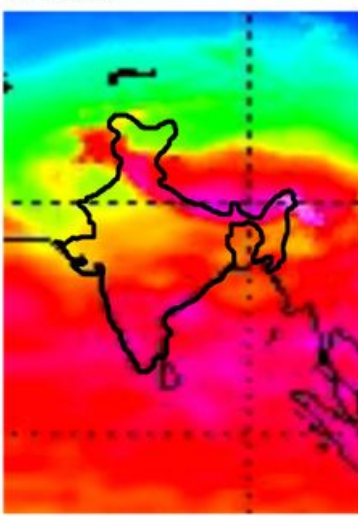

$15-4-2020$

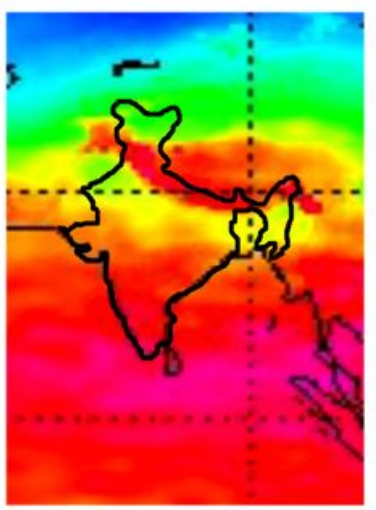

30-4-2019

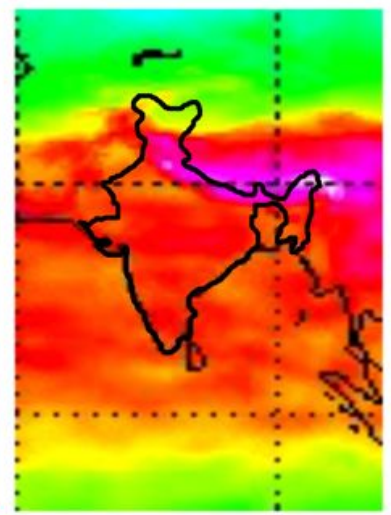

30-4-2020

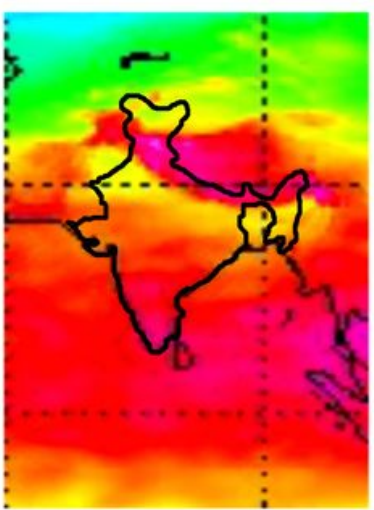

15-5-2019

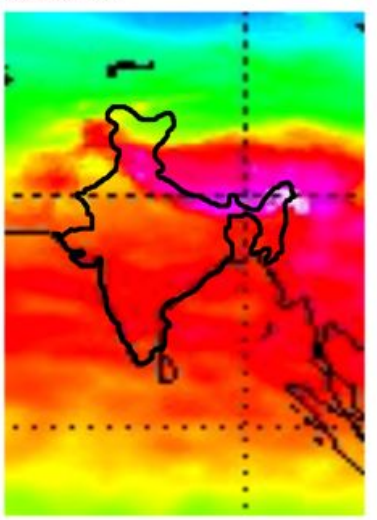

$15-5-2020$

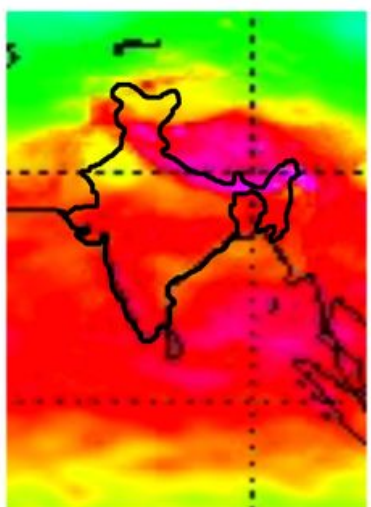

30-5-2019

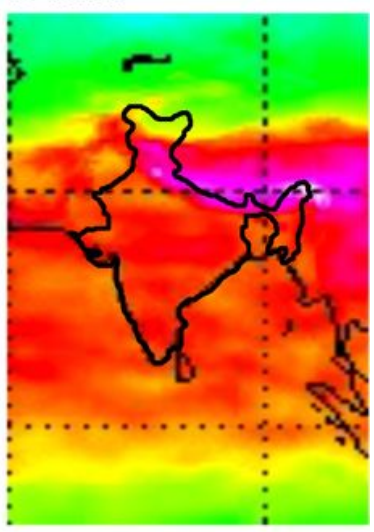

30-5-2020

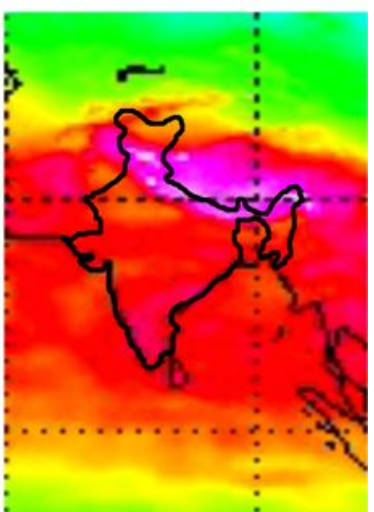

UVI value

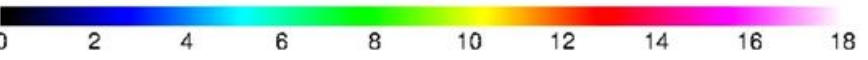

Figure 2

The alteration of ultraviolet index (UVI) throughout India during and pre lockdown phase (2019-2020). Note: The designations employed and the presentation of the material on this map do not imply the expression of any opinion whatsoever on the part of Research Square concerning the legal status of any country, territory, city or area o bbnhjr of its authorities, or concerning the delimitation of its frontiers or boundaries. This map has been provided by the authors. 


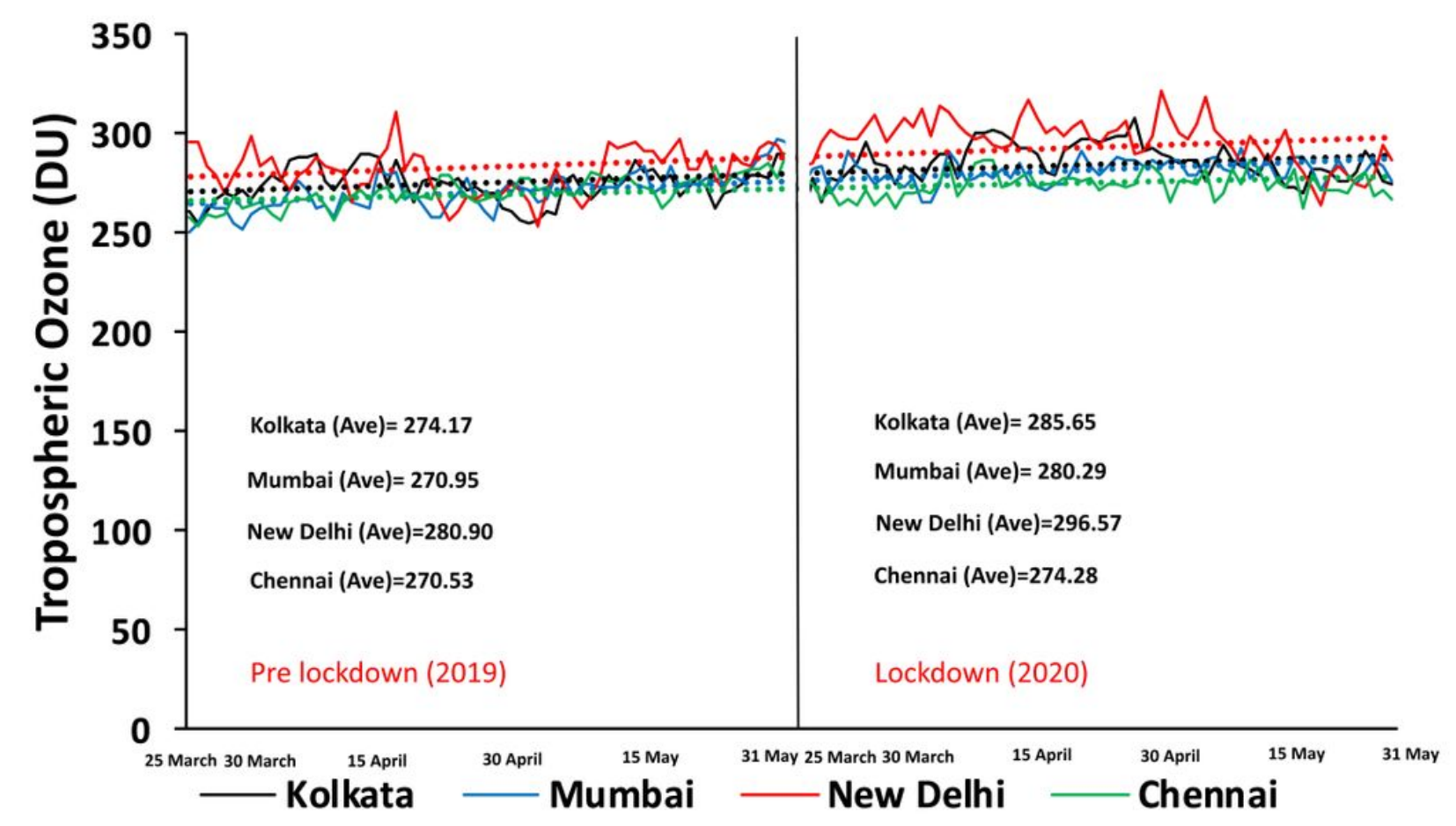

Figure 3

The changing pattern of tropospheric 03 through the sampling period (25th March - 31st May) during and pre lockdown period (2019-2020) 


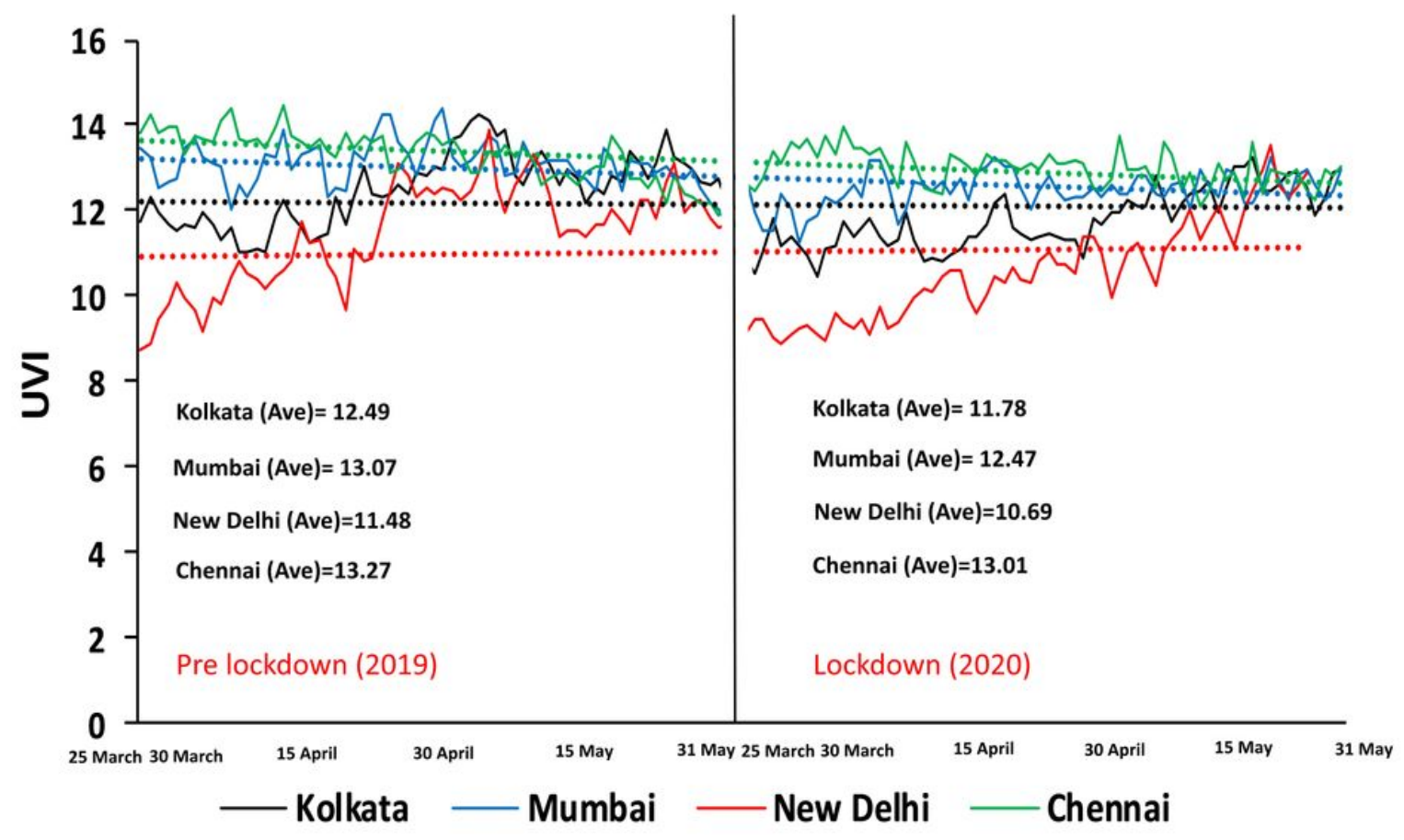

Figure 4

The variation of UV index (UVI) through the sampling period (25th March - 31st May) during and pre lockdown period (2019-2020) 


\section{New Delhi}

Pre lockdown (2019)

March.

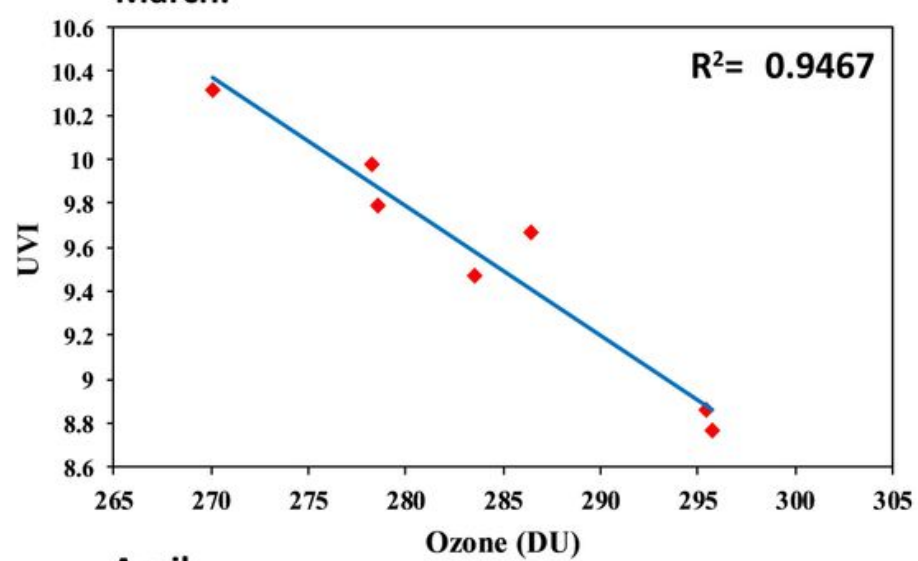

April.

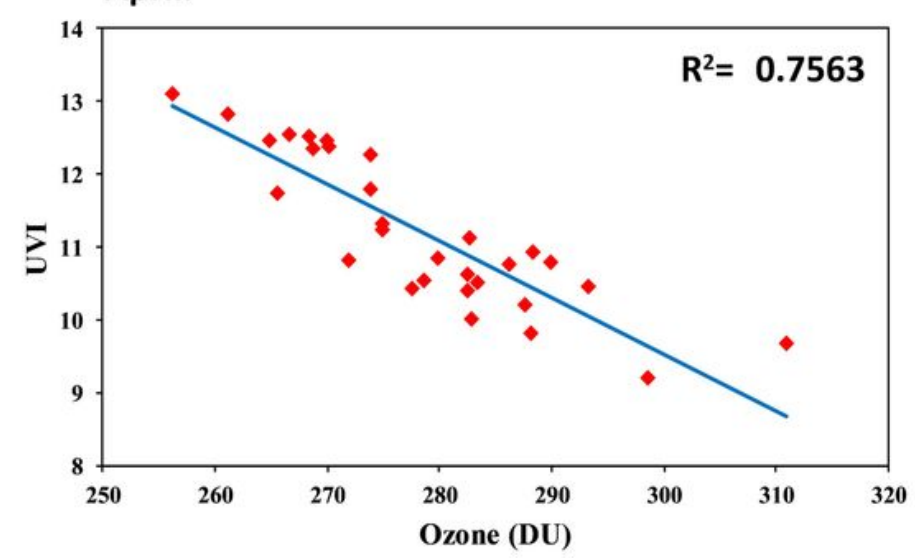

May.

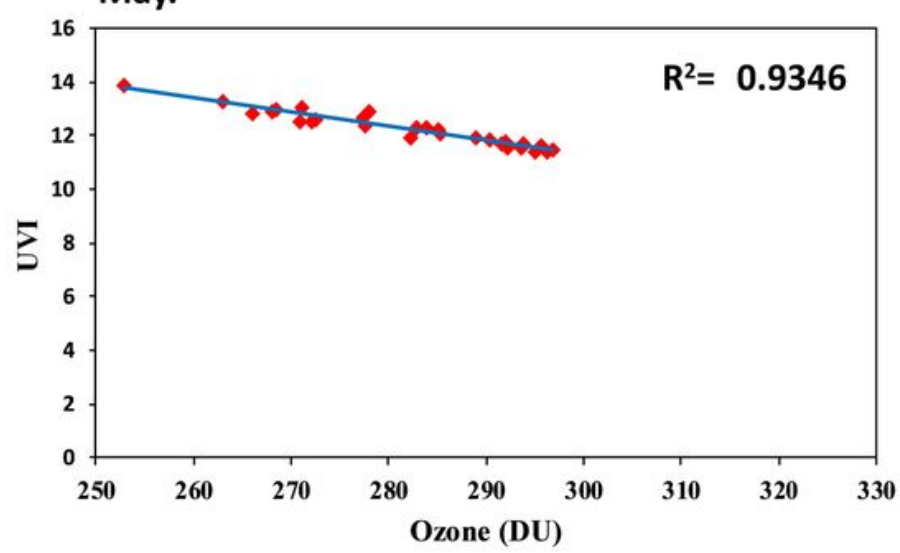

Lockdown (2020)

March.

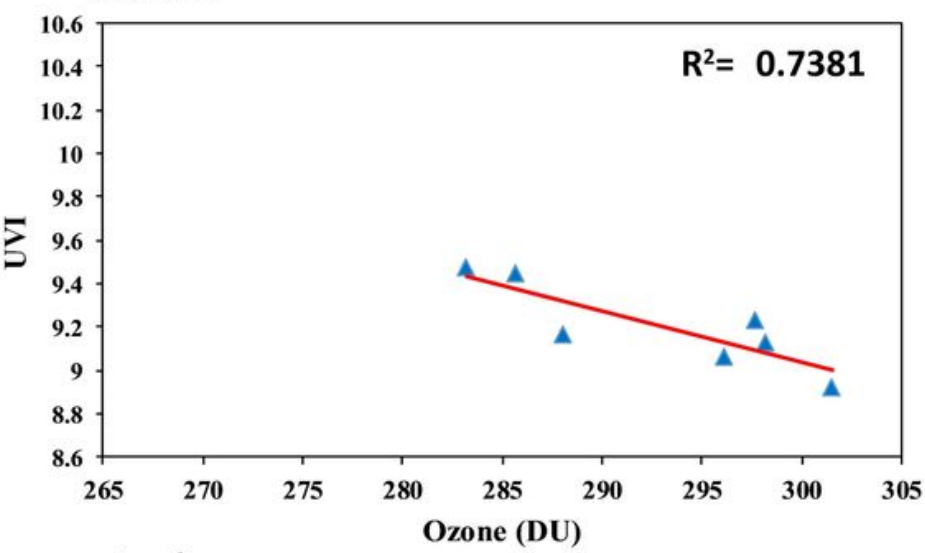

April.

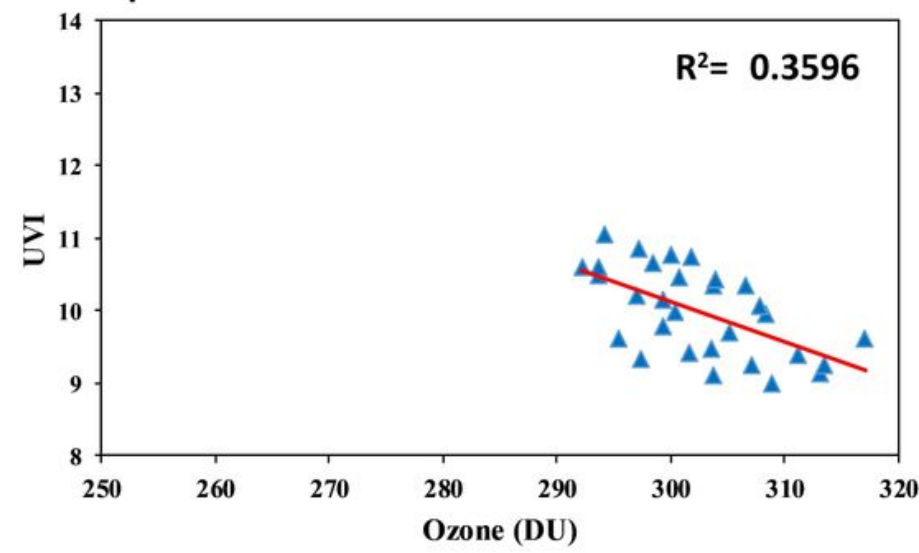

May.

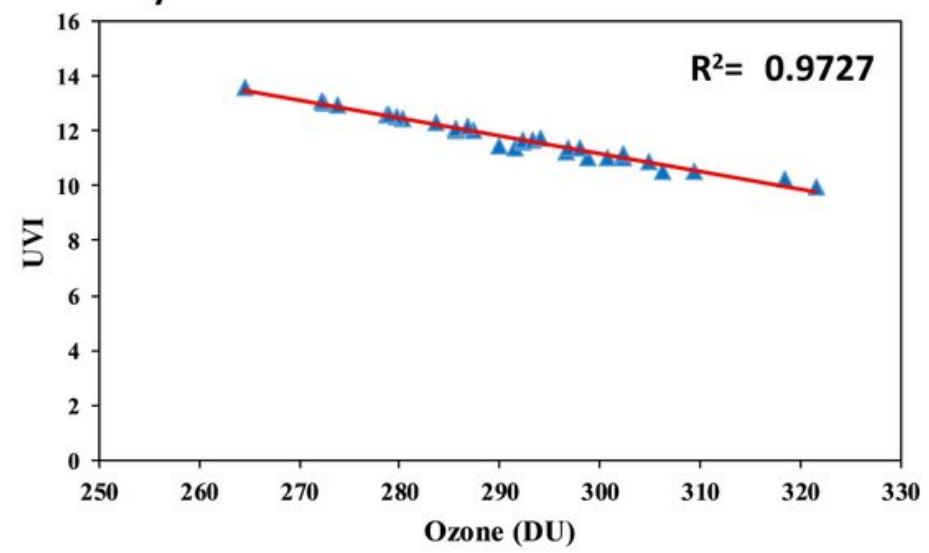

Figure 5

Correlation between tropospheric 03 and UV index over New Delhi during the sampling period in the year 2019 and 2020. 


\section{Kolkata}

\section{Pre lockdown (2019)}
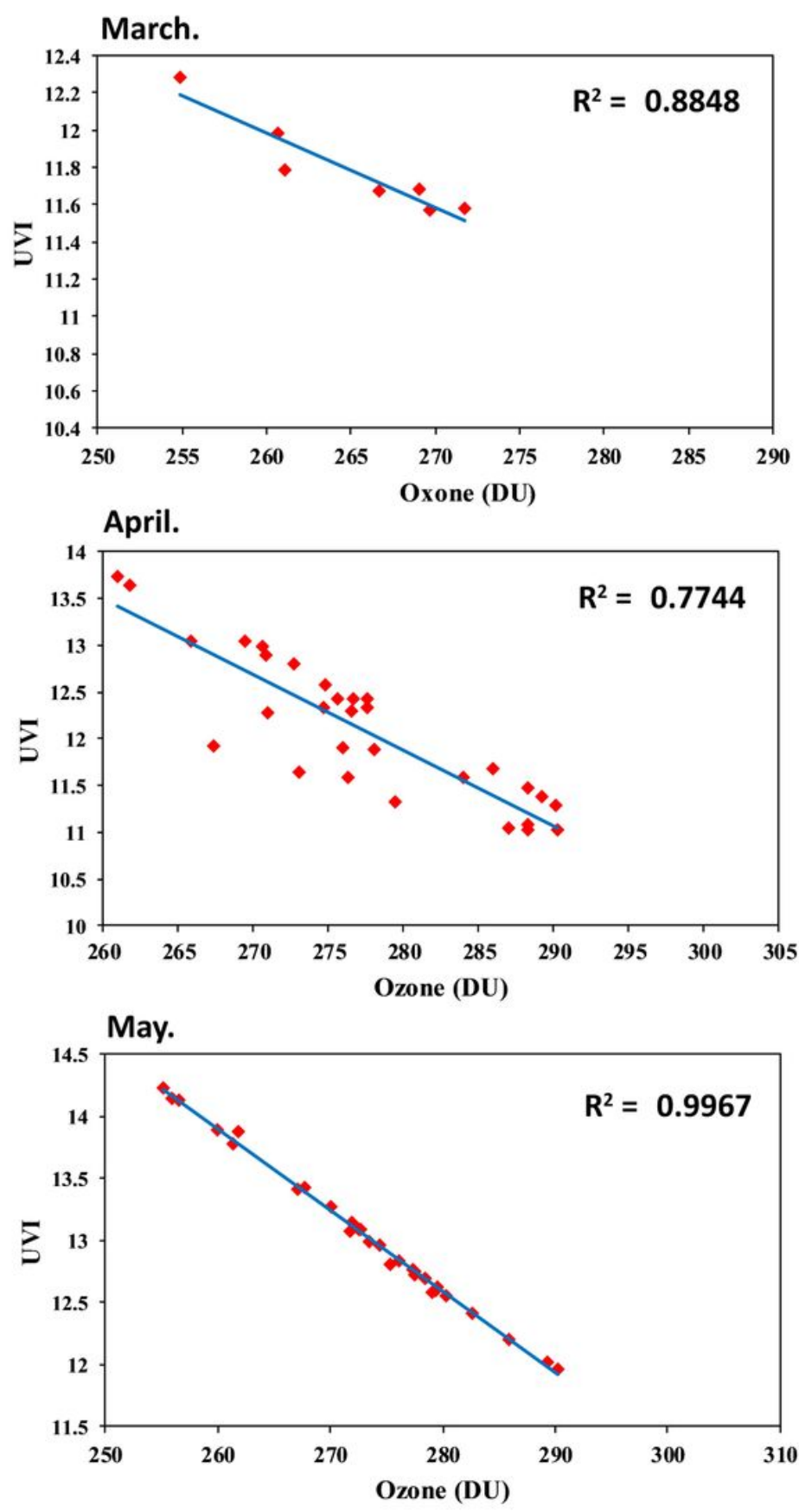

\section{Lockdown (2020)}

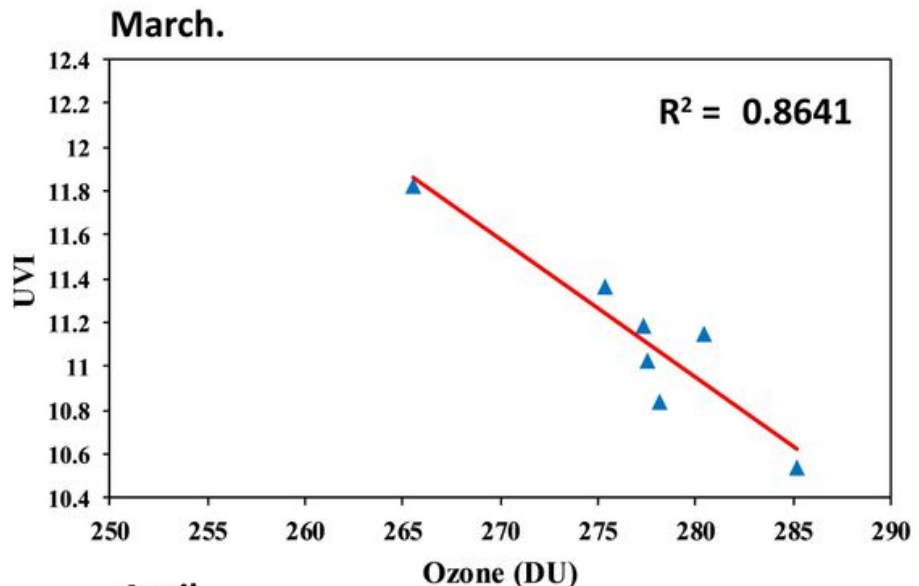

April.

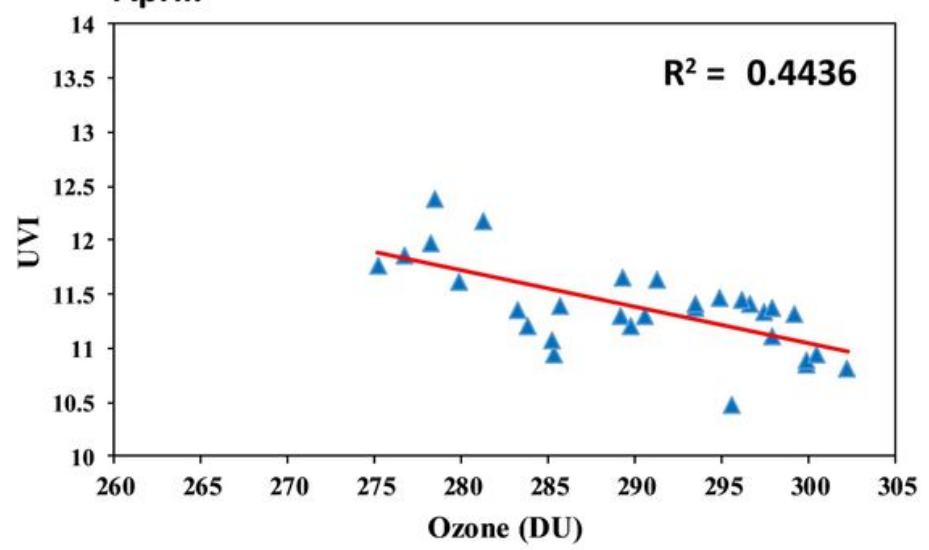

May.

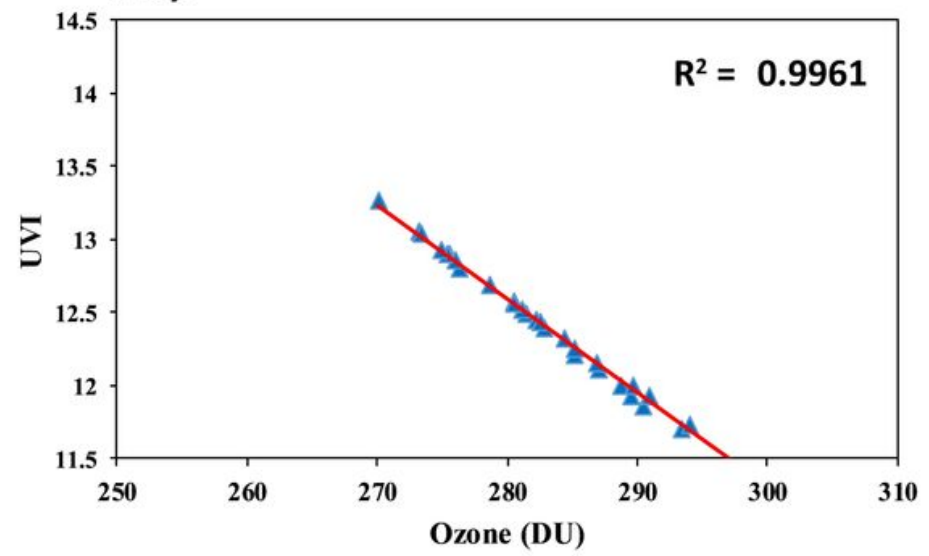

Figure 6

Correlation between tropospheric 03 and UV index over Kolkata during the sampling period in the year 2019 and 2020 
Pre lockdown (2019)

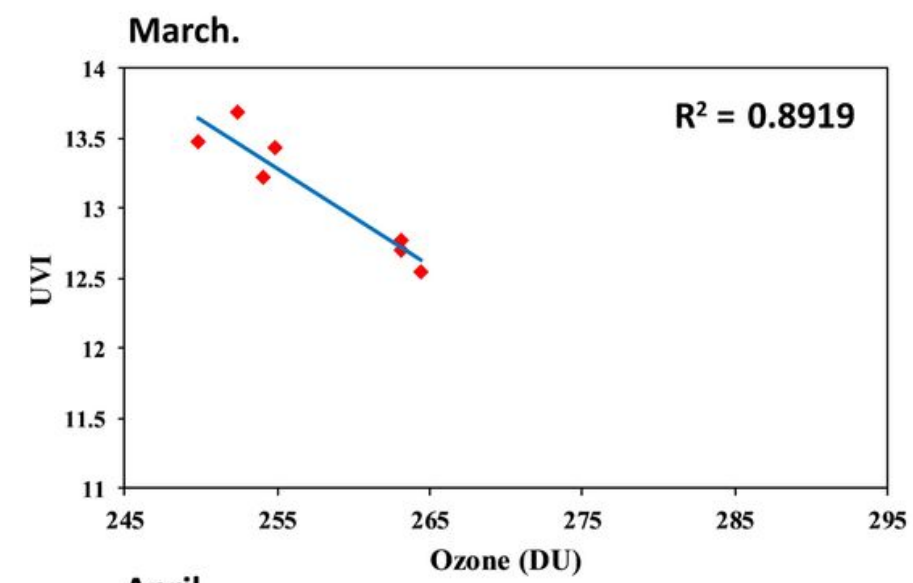

April.
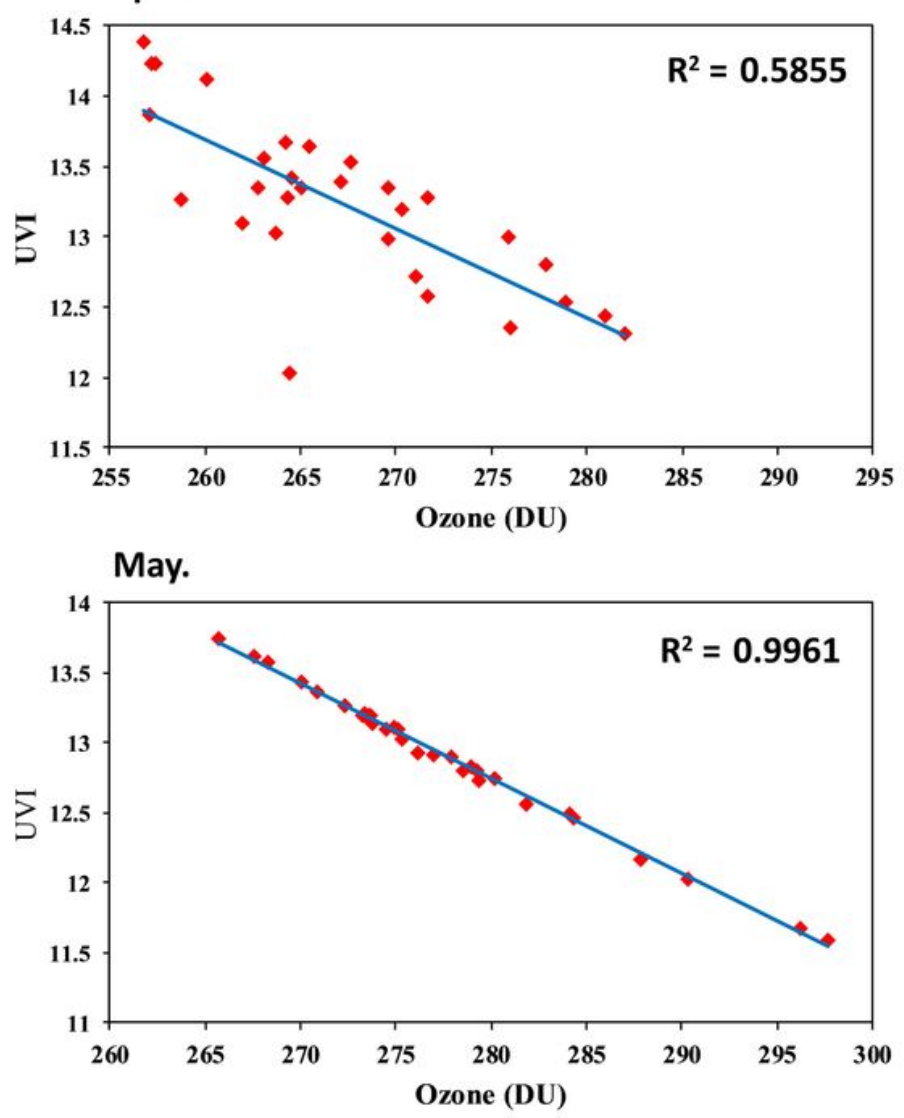

Lockdown (2020)

March.

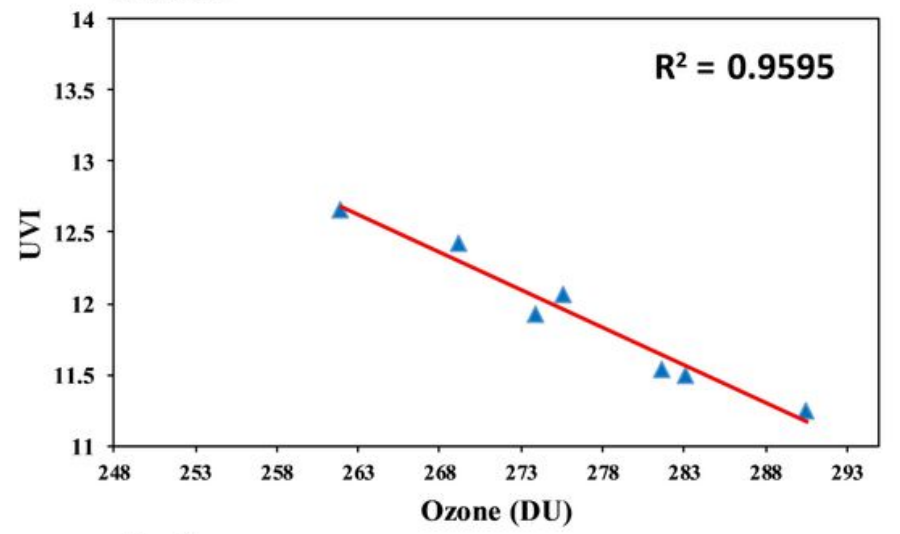

April.

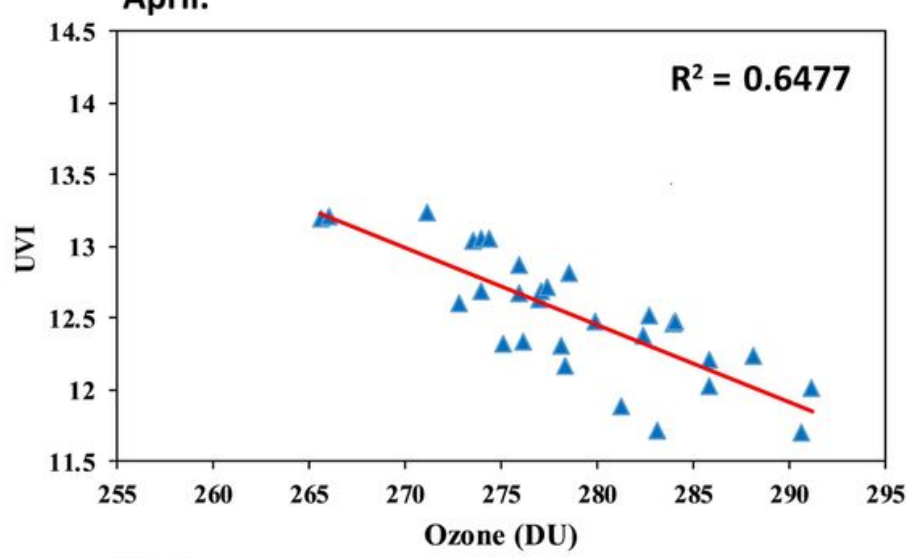

May.

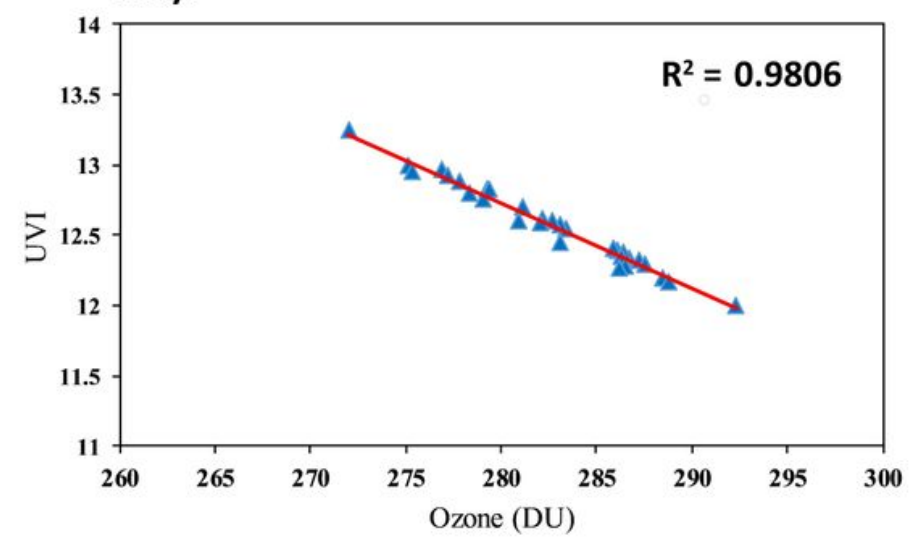

Figure 7

Correlation between tropospheric 03 and UV index over Mumbai during the sampling period in the year 2019 and 2020 


\section{Chennai}

Pre lockdown (2019)
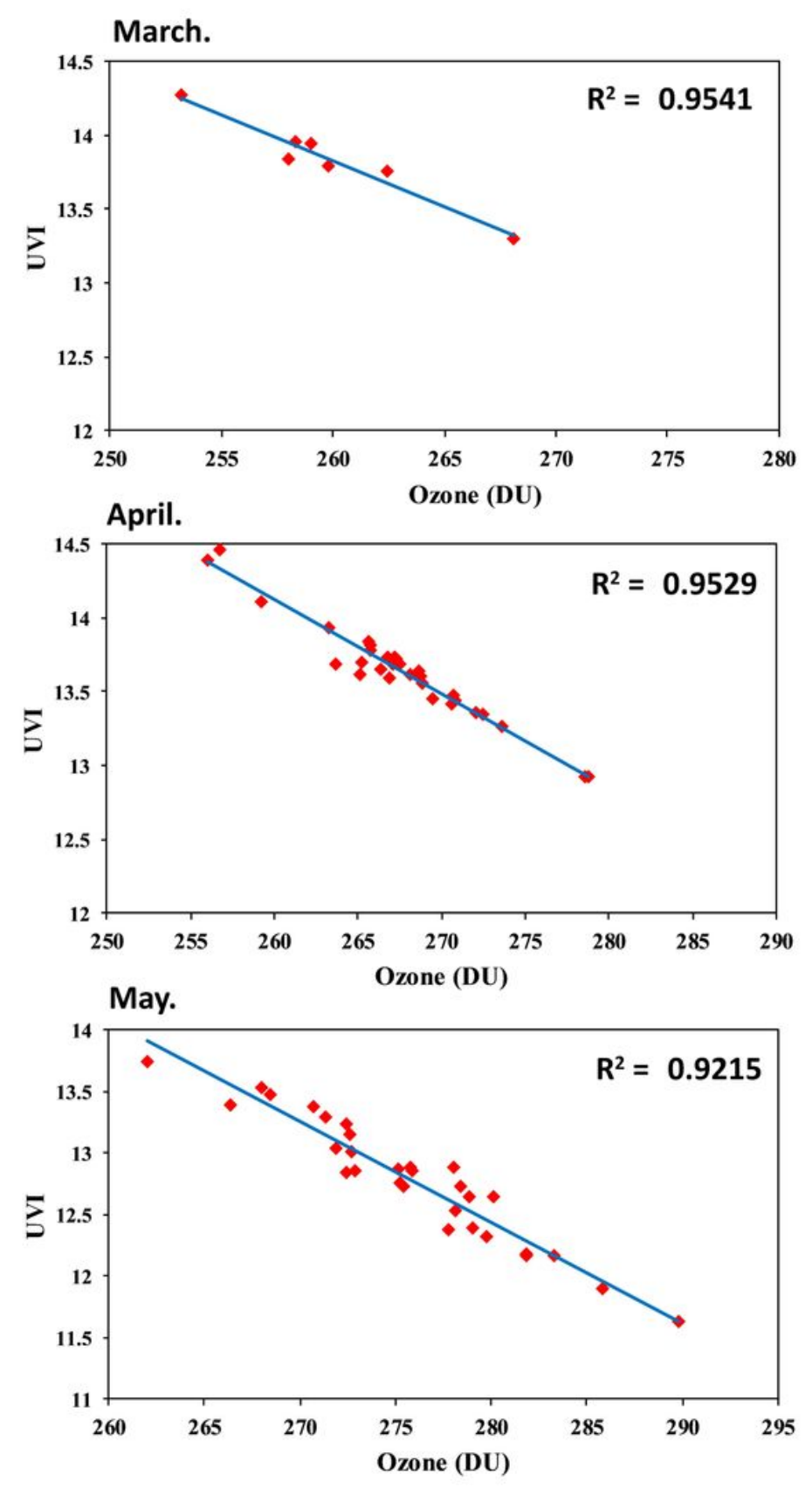

Lockdown (2020)
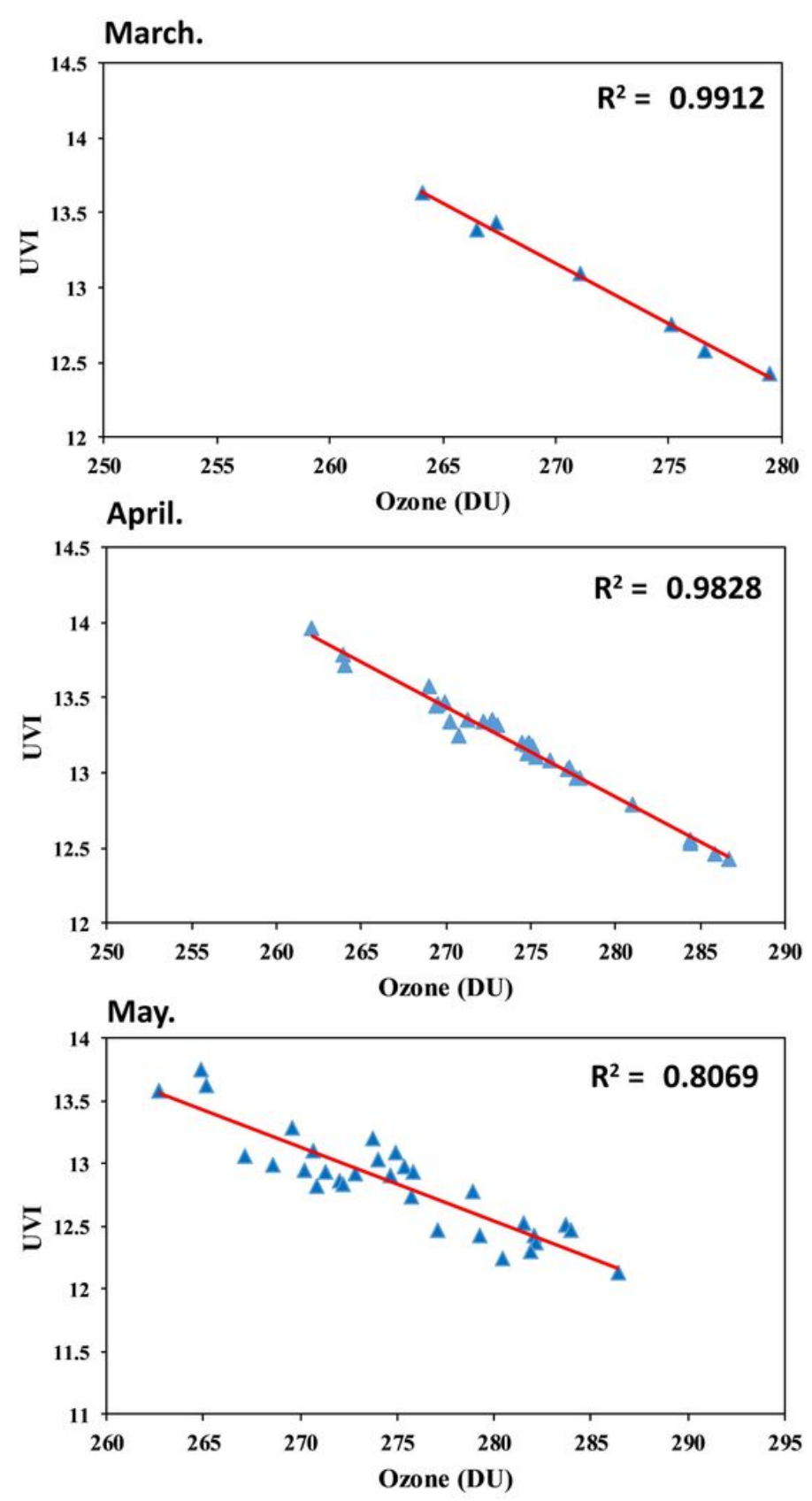

Figure 8

Correlation between tropospheric 03 and UV index over Chennai during the sampling period in the year 2019 and 2020 

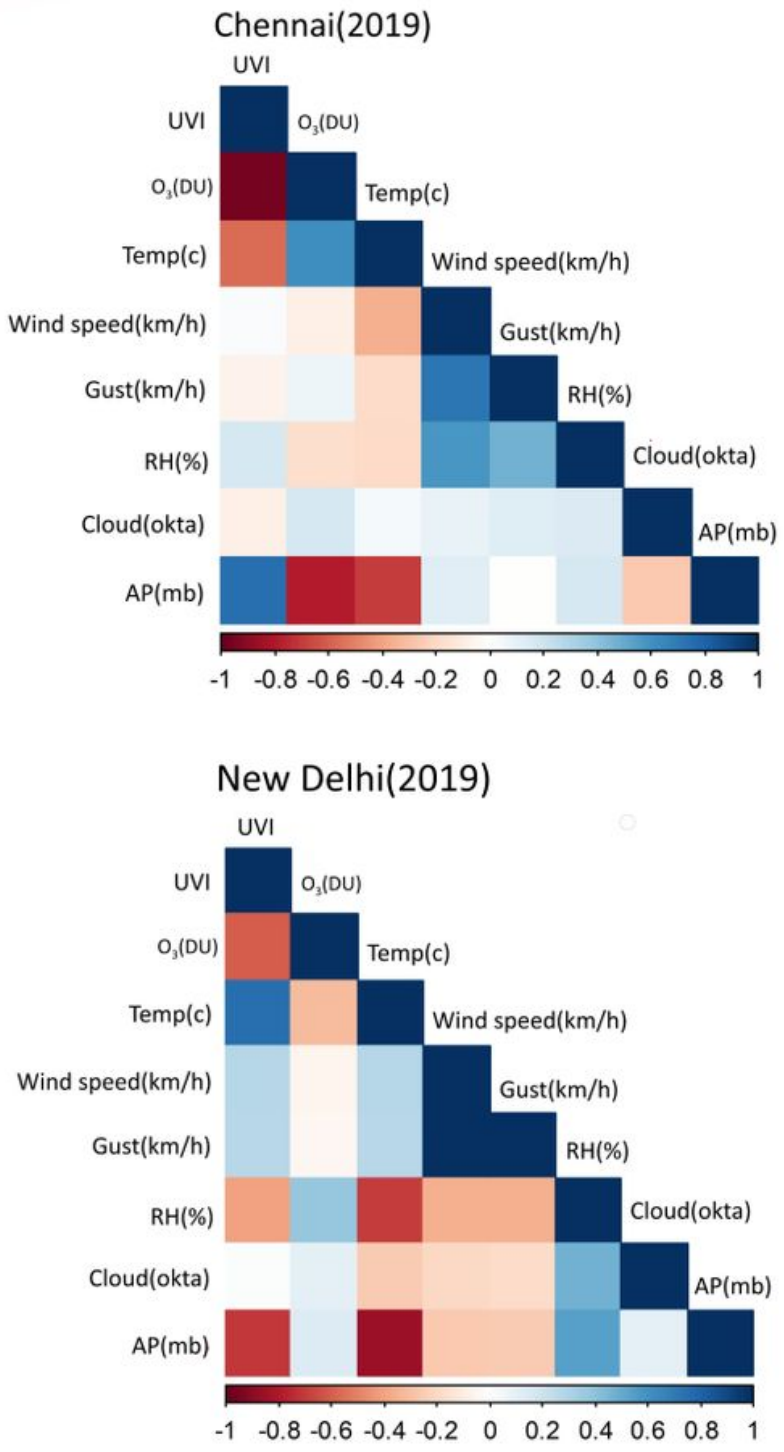
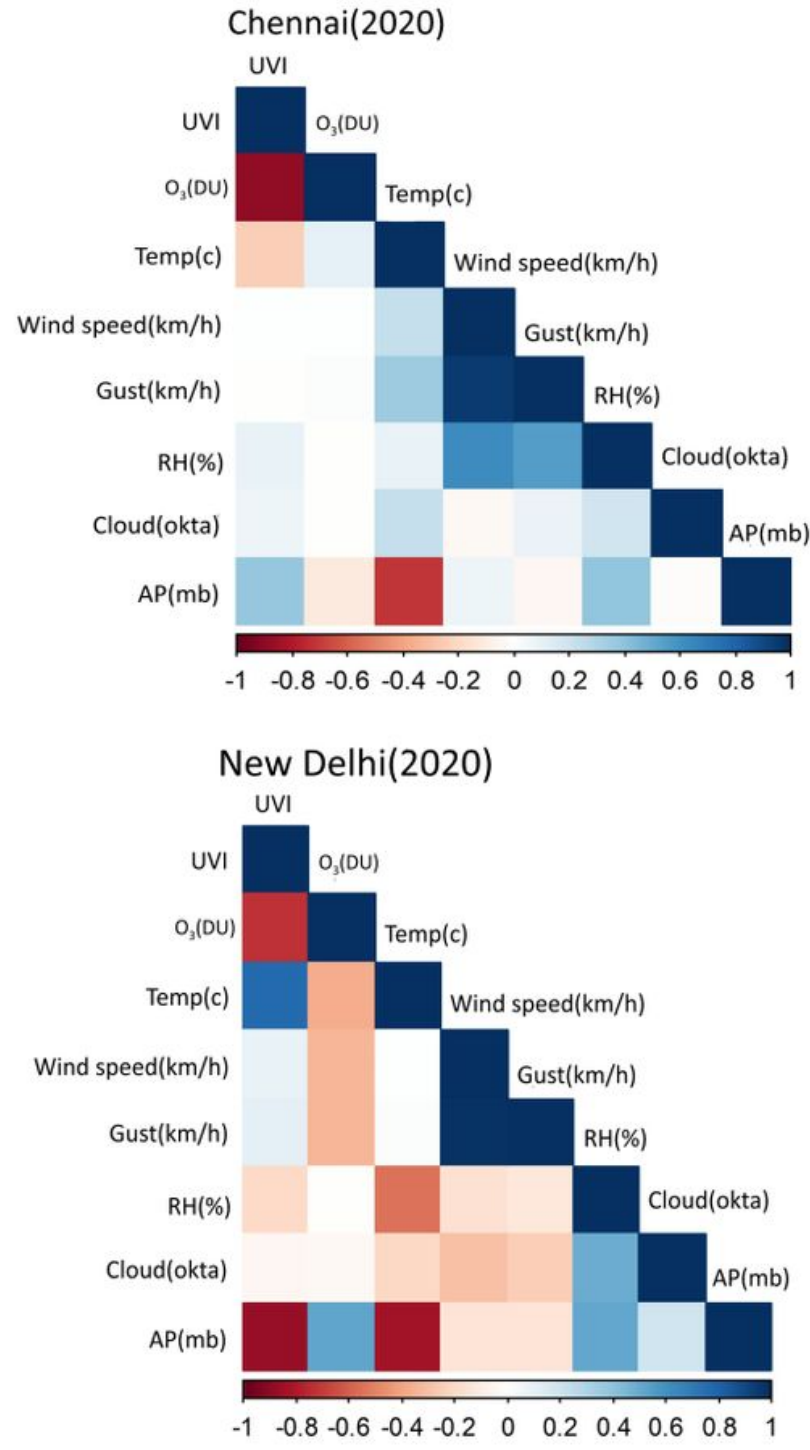

Figure 9

Correlation of UVI and 03 with climatological factors over Chennai and New Delhi during (2020) and prelockdown (2019) phase 

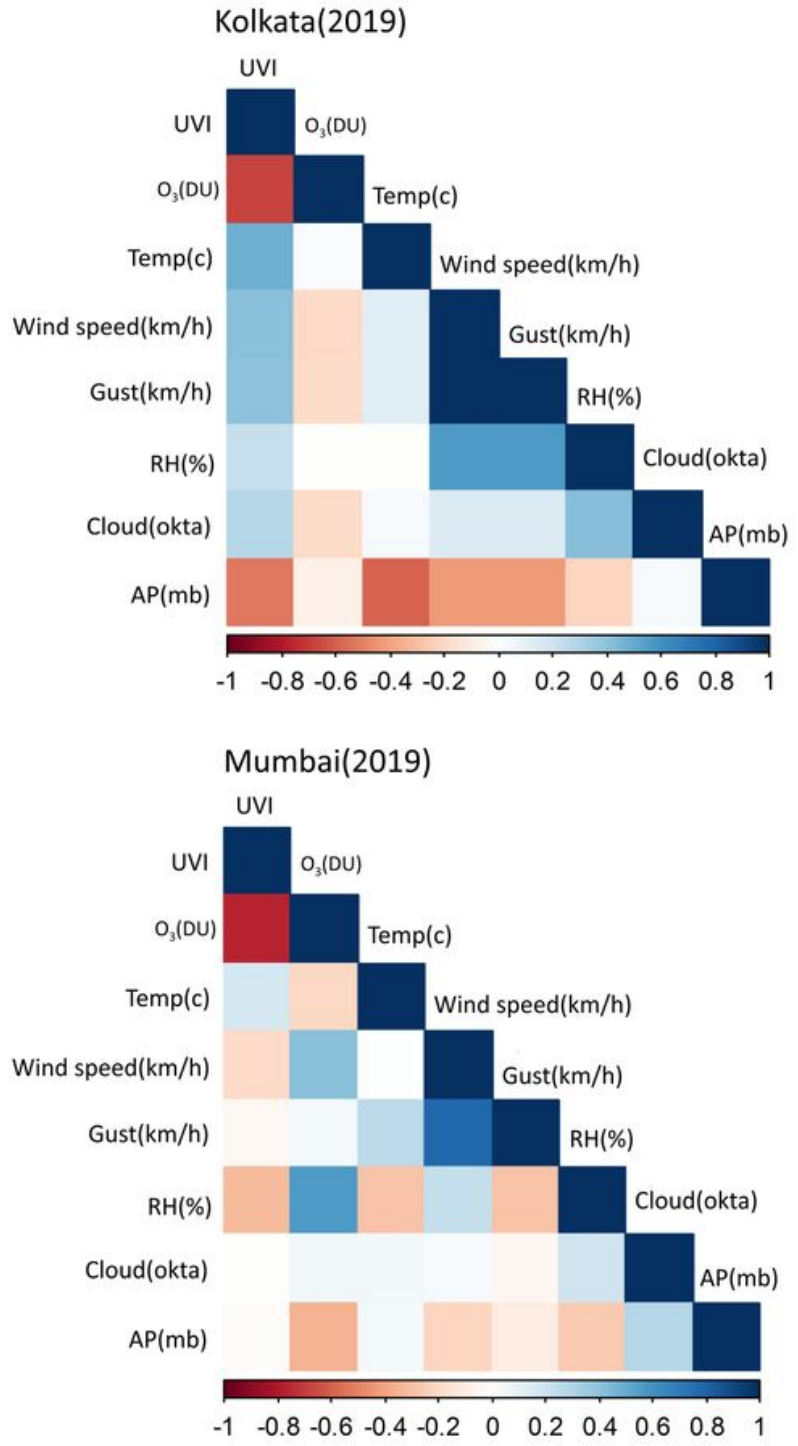

Kolkata(2020)

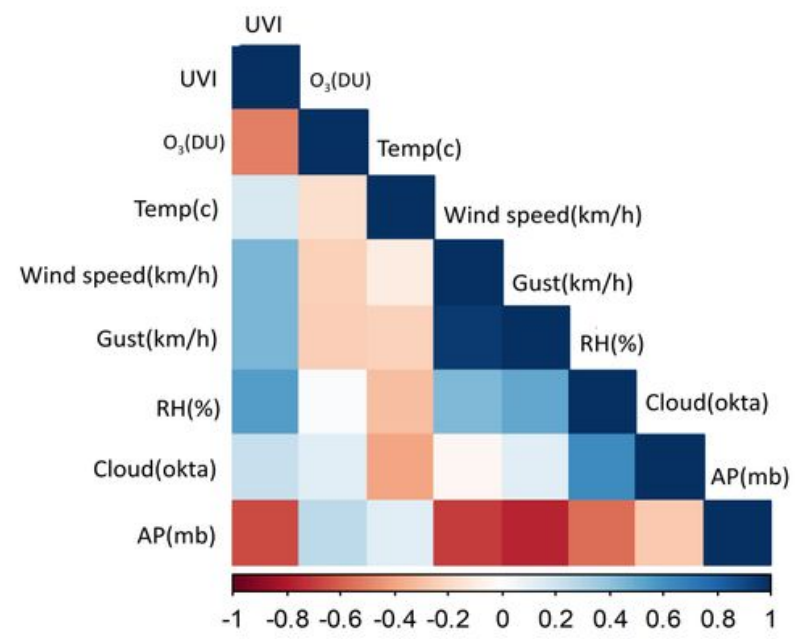

Mumbai(2020)

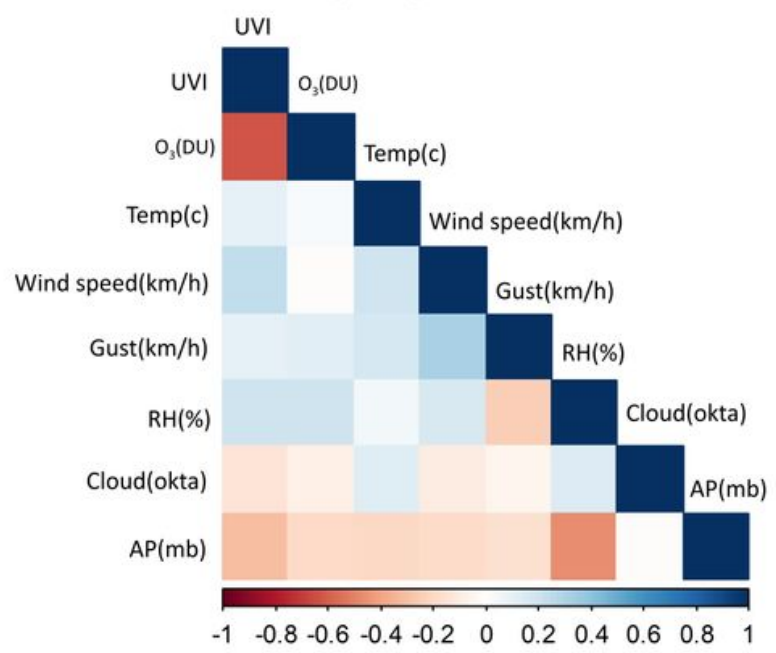

Figure 10

Correlation of UVI and 03 with climatological factors over Kolkata and Mumbai during (2020) and prelockdown (2019) phase

\section{Supplementary Files}

This is a list of supplementary files associated with this preprint. Click to download.

- Tables1Supplementarytable.docx

- TableS2Supplementarytable.docx

- TableS3Supplementarytable.docx

- TableS4Supplementarytable.docx

- TableS5Supplementarytable.docx

- Tables6Supplementarytable.docx 
- TableS7Supplementarytable.docx

- Tables8Supplementarytable.docx 